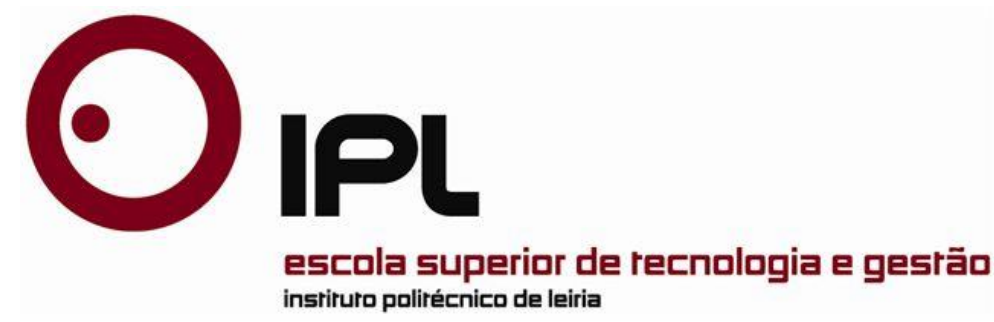

Dissertation

Master in International Business

\title{
Institutional effects on the ownership in cross-border acquisitions by African firms
}

\author{
José Carlos Pereira Rodrigues
}




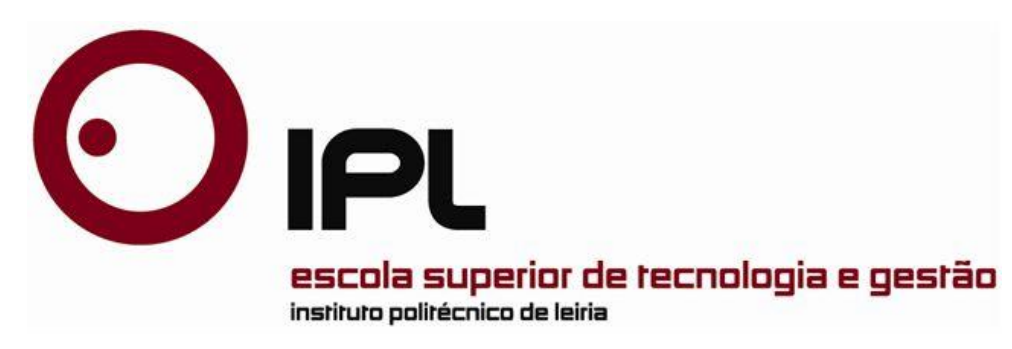

Dissertation

Master in International Business

\section{Institutional effects on the ownership in cross-border acquisitions by African firms}

\section{José Carlos Pereira Rodrigues}

Master's Dissertation under the supervision of Professor Manuel Portugal Ferreira, and Professor João Carvalho Santos, Escola Superior de Tecnologia e Gestão of the Polytechnic Institute of Leiria. 


\section{Acknowledgements}

This work could not be possible without the guidance, demand, support, careful comments and suggestions of Professor Manuel Portugal Ferreira and Professor João Carvalho Santos.

Specially, I thank Professor Manuel Portugal Ferreira for his effort in fostering my inner brainstorming activities always aiming at continuous improvement. 


\section{Abstract}

Research suggests that context matters for MNEs' international business strategy. MNEs' strategies vary when different intertwined contexts interact with each other. While International Business scholars understand well the influence of the institutional environments on firms' international strategies and operations, some contextual differences are less understood as is the case involving African countries and firms. In this study I investigate how different institutional contexts and legitimacy challenges combine to impact ownership strategic choices of African firms in their cross-border acquisitions (CBAs). Specifically, I study the influence of the host country institutional development and two institutional dimension distances: administrative distance and knowledge distance. Methodologically, I use a sample of 314 CBAs made by acquirers from 24 African countries in 71 host countries worldwide to test a number of theoretically driven hypotheses. This study contributes to our understanding of how foreign investors from less institutionally developed countries that are more likely to face higher legitimacy barriers use ownership strategies to achieve legitimacy abroad.

Keywords: African acquisitions; African institutional environment; African multinationals; Cross-border acquisitions; Ownership. 


\section{List of figures}

Figure 1. Conceptual model . 


\section{List of tables}

Table 1. Number of acquisitions by country: 2009 to $2015 \ldots \ldots \ldots \ldots \ldots \ldots \ldots . . . \ldots 28$

Table 2. Number of cases by percentage of ownership acquired ............. 29

Table 3. Description of variables .................................... 35

Table 4. Descriptive statistics ....................................... 38

Table 5. Correlations ............................................... 39

Table 6. Logistic regression results (African CBAs) ..................... 42

Table 7. OLS regression results (African CBAs) ............................. 45

Table 8. Logistic regression results (AfMNEs CBAs in Africa) ................. 48

Table 9. Logistic regression results (AfMNEs CBAs out of Africa) .......... 51

Table 10. Logistic regression results (South African CBAs) ................. 54

Table 11. Logistic regression results (non-South African CBAs) ............. 58 


\section{List of acronyms}

AfMNE - African Multinational Enterprise

CBA $\quad-$ Cross-Border Acquisition

FSA $\quad-\quad$ Firm specific advantages

IDI $\quad-\quad$ Institutional Development Index

M\&A $\quad-\quad$ Merger and Acquisition

MNE $\quad-\quad$ Multinational Enterprise

OLS $\quad-\quad$ Ordinary Least Squares

SIC $\quad-\quad$ Standard Industry Classification 


\section{Index}

ACKNOWLEDGEMENTS

ABSTRACT III

LIST OF FIGURES

LIST OF TABLES $\quad$ V

LIST OF ACRONYMS VI

INDEX

1. INTRODUCTION 1

2. LITERATURE REVIEW 5

$\begin{array}{ll}2.1 \text { Ownership in CBAs } & 6\end{array}$

2.2 Institutional differences across countries 9

2.3 Gaining legitimacy in foreign countries 11

3. HYPOTHESES 15

3.1 Administrative distance 16

$\begin{array}{lr}3.2 \text { Knowledge distance } & 18\end{array}$

$\begin{array}{ll}3.3 \text { Target institutional development } & 20\end{array}$

4. METHOD 27

$\begin{array}{ll}\text { 4.1 Data and sample } & 27\end{array}$

4.2 Variables 30

4.3 Procedures of analyses 36

5. RESULTS 37

5.1 Robustness checks 43

5.2 Post-hoc analyses $\quad 46$

6. DISCUSSION 59

$\begin{array}{ll}\text { 6.1 Limitations and future research avenues } & 64\end{array}$

6.2 Managerial implications $\quad 65$

7. CONCLUSION 67

$\begin{array}{ll}\text { REFERENCES } & 70\end{array}$ 
(This page was intentionally left blank) 


\section{Introduction}

Firms entering foreign markets have to make decisions pertaining to the ownership of their foreign operations. The ownership stake is an important strategic decision because it determines firms' degree of control, resource commitment, and risks over their operations in a foreign host country (Laufs \& Schwens, 2014). Despite the importance of ownership, both given the long term implications and also the short term disbursement of financial resources it entails, there are still some gaps in the existing knowledge as put by Ando (2012, p. 260) "not much is known about the effect of institutional dissimilarity on the choice of ownership structure of foreign subsidiaries". Moreover, our understanding is still rather limited in understanding how multinational corporations from extremely institutionally underdeveloped countries are able to overcome what could be unsurmountable issues pertaining to the lack of legitimacy. This lack of legitimacy is even more likely to be majored when entering the more developed countries of Europe and the US.

Africa presents an institutionally underdeveloped environment that may magnify the challenges faced by MNEs for achieving legitimacy in their international expansion. Legitimacy is achieved when MNEs' actions and activities are generally perceived by the environment as desirable and appropriate (Suchman, 1995, Kostova \& Zaheer, 1999; Human \& Provan, 2000). Host countries have their own standards in judging MNEs behavior, which are usually different from those applied to domestic firms during the legitimating process (Kostova \& Zaheer, 1999). The African continent is known from suffering from political instability, corruption, poverty and ongoing conflicts within and across many countries borders (Mol, Stadler \& Ariño, 2016). Hence, African multinationals (AfMNEs) are likely to be perceived pejoratively by potential business partners abroad. AfMNEs might be seen in the host country as firms that lack proper requirements in order to bring value to a business relationship, for lacking technology and an overall sense of distrust which is likely due, at least to some extent, to the reflection of the many economic, political and corruption problems across the African continent. That is, the reality that AfMNEs face at home might raise legitimacy problems when entering foreign countries and especially more developed countries. 
The extent of the host country institutional pressures over AfMNEs vary according to the perceived cross-country institutional differences (Berry, Guillén \& Zhou, 2010) and the level of institutional development of the host country (Hernández \& Nieto, 2015; Meyer, Ding, Li \& Zhang, 2014). Cross-country differences at the regulatory domain, for instance, require additional efforts to attain local legitimacy because AfMNEs must comply with unfamiliar legal frameworks and market practices. Moreover, significant cross-country differences regarding technology and know-how can raise fears in the host country of losing technological preponderance or competitive advantages (Meyer et al., 2014). These institutional pressures, as I will advance, are probably moderated by the level of institutional development of the host country because of the institutional voids that "affect entry mode choice as underdeveloped institutions drive the costs of establishing wholly-owned ventures" (Meyer, 2001, p. $365)$.

Ownership strategies enhance AfMNEs' ability to successfully deal with the host country institutional pressures (Delios \& Henisz, 2000). How ownership strategies help African firms cope with their legitimacy challenges is a theme that deservers further research since "institutional pressures do not apply homogeneously to all foreign firms" (Meyer et al., 2014, p. 1007). In this study I consider the effect of the host country institutional development and two dimensions of institutional distance that were previously identified by Berry et al. (2010) - administrative distance and knowledge distance - to investigate how different ownership strategic choices allow parent firms coming from Africa to achieve legitimacy abroad. I will put forth the proposition that the ownership strategies are strategic responses to the institutional distance that separates the AfMNEs from the host countries where they are investing. To explore into the ownership I use a sample of cross-border acquisitions conducted by AfMNEs.

That is, in essence, using a panel dataset consisting of 314 acquisitions made by acquirer firms from 24 African home countries in 71 host countries, from 2009 to 2015, I investigate how AfMNEs use ownership strategies to effectively deal with their legitimacy challenges abroad. Post-hoc analyses with specific subsamples add further theoretical and empirical insights.

This study has thus four main contributions to the literature. First, when considering home and host environments MNEs are faced with, our understanding about the relationship between the presence or absence of institutional voids and the distance between more specific institutional dimensions is still scarce. I argue that 
integrating between the concept of institutional distance and the concept of legitimacy "as the acceptance of the organization by its environment [is] vital for organizational survival and success" (Kostova \& Zaheer, 1999, p. 64) - permits improving our understanding of the MNEs' strategic choices when embracing international business activities.

Second, this study highlights the potential moderator effect of the level of host country institutional development over institutional distance in MNEs' ownership choices. More specifically, I put forth that gaining, maintaining and repairing legitimacy requires different strategies in institutionally developed countries than those best suited for underdeveloped countries (Suchman, 1995). Institutionally developed environments present more market friendly regulations and practices which, coupled with higher levels of legal investors' protection, enable MNEs to easily overcome their liability of foreignness. However, more developed countries are also more likely to look with suspicion to AfMNEs.

A third contribution arises from enhancing our understanding over the African continent and the AfMNEs' strategic behaviors. I am thus able to provide insights on how the nature of the institutional environment drives AfMNEs strategies. In this regard it is useful to examine whether and how the ownership choices of AfMNEs may vary when investing in other African countries and when investing out of Africa.

A final contribution to the debate on institutional legitimacy. In fact, AfMNEs are more likely to have much greater obstacles to their legitimacy in the foreign expansions. Indeed these obstacles may be even greater by expanding through cross-border acquisitions in more institutionally developed countries. How these a priori illegitimate AfMNEs are able to gain legitimacy is an endeavor worth researching even for its implications to a wider variety of countries such as those in Latin America and even the poorer countries in Asia.

The study is organized in seven parts as follows. The next part addresses the literature review over the relevant themes under analysis: (1) ownership in CBAs; (2) institutional differences across countries; and (3) gaining legitimacy in foreign countries. The third part proceeds with the development of hypotheses. The method, in the fourth part, includes presentation of the data, sample and variables. The fifth part shows the results of the tests of the hypotheses. The sixth part entails a broad discussion of the results linking back to the theory. The dissertation concludes with an outline of final remarks. 
(This page was intentionally left blank) 


\section{Literature review}

Institutional theory addresses the processes by which structures become acting as guidelines for social behavior, supported by three "pillars" (regulative - laws, rules; normative - norms; and cognitive - cultures, ethics), and examining interactions from micro interpersonal to macro global frameworks (Scott, 2004). Institutions are commonly known as the "rules of the game", whether formal (laws, rules and regulations) or informal (norms, cultures and ethics), placing constraints to human interaction and shaping competition (Peng, Sun, Pinkham \& Chen, 2009). Accordingly, firms are subjected to a set of pressures for compliance with their host environments. Institutional dissimilarities emerge from a variety of national differences that each different host country might present to a given MNE when considering to pursuit its business activities abroad (Ando, 2012). The strength of the institutional pressures presented by the host country is a determinant of the costs of doing business abroad (Chan, Isobe \& Makino, 2008).

Strong or weak institutional settings present different challenges for MNEs success. Well-developed institutional environments are those that are stable, credible and fostering of market supporting activities (Peng, 2002; Hernández \& Nieto, 2015), making it less costly for MNEs to engage in business activities. Less developed, or weak, institutional environments are those where deploying non-market capabilities enhance MNEs' competitive advantages, such as lobbying and government relationships (Estrin, Meyer, Nielsen \& Nielsen, 2016), and make market transactions costly, whether because transformation is less efficient and/or MNEs need to protect their assets from expropriation hazards (Chan et al., 2008; Delios \& Henisz, 2000).

Cross-country institutional distances inhibit MNEs from achieving legitimacy across borders and influence MNEs ownership choices (Xu and Shenkar, 2002). These distances pose hurdles that might be magnified by the existence of institutional voids in the host country. For successfully doing business abroad, MNEs must rely on their ability to overcome institutional differences between their home and host countries, while seeking to understand how to obtain legitimacy for their international activities (Meyer et al., 2014). Delios and Henisz (2000) emphasized that ownership is one strategic option that allows MNEs to cope with their institutional environment. 


\subsection{Ownership in CBAs}

MNEs can achieve legitimacy by using ownership strategies; albeit the effectiveness of ownership strategies may also vary according to the magnitude of the institutional pressures exerted by the host country (Meyer et al., 2014). Focusing in a particular type of MNE - MNEs that had some degree of government ownership, Meyer et al. (2014) outlined how the idiosyncrasies of state-owned MNEs (versus privately held firms) lead to different legitimating pressures exerted by the host country agents over the firm. These authors explain that "institutional pressures do not apply homogeneously to all foreign firms" (Meyer et al., 2014, p. 1007) and that those pressures might be quite significant when entering technologically and institutionally advanced countries. Equity mode control emerges as a way for managing the magnitude of those pressures and thus the extension of the legitimacy challenges that MNEs will face in the host country (Meyer et al., 2014; Delios \& Henisz, 2000).

MNEs might aim at getting involved in a partnership for overcoming their legitimacy challenges abroad, but differences between countries may inhibit their endeavors. Cross-country differences in regulatory environments, such as differences between free market economies and centrally directed economies, eventually raise distrust among host country legitimating actors regarding the MNE intentions and capabilities (Meyer et al., 2014). In a similar vein, host country's agents in more technologically developed countries may raise fears regarding the possibility of technological leakage to foreign MNEs (Meyer et al., 2014). When an AfMNE engages in a CBA in a technologically advanced country it likely faces higher institutional pressures hindering the achievement of legitimacy than those that might be posed to another foreign MNE coming from a technologically advanced country. In this instance, for an AfMNE engaging in a CBA, legitimacy pressures might loom for conditioning the firm's choices over the desirable level of equity control of the venture. MNEs might need to sacrifice ownership in exchange for legitimacy since lower levels of ownership help controlling adverse reactions from host country legitimating actors (Meyer et al., 2014) while enhancing its local identity and legitimacy.

The literature offers several studies over MNEs preferences for partial or full ownership but has been less explicit on how ownership may be a legitimacy creating strategy. Full ownership tends to be sought when acquirers identify greater needs of controlling its subsidiary operations, such as in situations when there is a substantial MNE's resource commitment and managers' perception of the risks involved is high 
(Xu \& Shenkar, 2002; Chari \& Chang, 2009; Kedia \& Bilgili, 2015). The acquirers seek complete control over the operations in order to offset the risks involved and the liability of foreignness. Conversely, Dikova (2009, p.41) argued that "ownership strategy is a useful tool in reducing unfamiliarity hazards" and states that "shared ownership can reduce the costs associated with liability of foreignness or environmental uncertainty". Partial ownership can also be explained under the real options theory approach. De Villa, Rajwani and Lawton (2015, p. 423) stated that "partial acquisitions provide a better combination of characteristics when the option to grow and the option to abandon are important". When there are higher levels of country differences the involvement of host country partners may enable access to complementary resources while sharing risks, and providing the acquirer with the flexibility to increase its foreign country commitment or abandon endeavor at a lower cost (Xu \& Shenkar, 2002; Chari \& Chang, 2009; Kedia \& Bilgili, 2015). However, the choice for a partial ownership entails some costs because the acquirer firm will not be able to fully integrate the target, will have less control, and may be exposed to opportunistic behaviors by the local partners (Chari \& Chang, 2009; Kedia \& Bilgili, 2015). Hence, partial ownership helps achieving legitimacy abroad but often demands higher governance costs due to efforts monitoring and coordinating subsidiary operations (Delios \& Henisz, 2000), while full ownership allows for greater operational control.

The effect of institutional distance on the choice of ownership depends on MNEs' goals for obtaining legitimacy and operational efficiency. Some authors suggest that higher levels of institutional distance between home and host countries likely lead to lower levels of equity sought (Chari \& Chang, 2009) because institutional distances between countries, such as a large cultural distance, will likely require the involvement of local partners in order to mobilize local legitimacy and offset foreign environment uncertainties (Xu \& Shenkar, 2002). Conversely, other authors stand that higher institutional distances present higher levels of risk and uncertainty inducing managers to choose higher ownership in order to improve the subsidiaries chances of survival (Gaur \& Lu, 2007). Institutional distance raise external uncertainties and challenges requiring adjustments from the acquirer firm in order to obtain legitimacy in the host country because legitimacy "will allow for relatively easy transfer of technology, organizational practices, and other resources across organizations, making the entire acquisition process faster and less complicated" (Elango, Lahiri and Kundu, 2013, p. 5). 
The direction of the institutional distance becomes crucial to enhance our understanding over how those differences apply regarding MNEs' strategic choices (De Beule, Elia \& Piscitello, 2014; Hernández \& Nieto, 2015). Considering the regulatory development in the host country, Hernández and Nieto (2015) pose that MNEs facing higher developed environments are able to easily adapt as the distance grows because environments will present less uncertainty. Moreover, these actors consider that when the legitimacy criteria (which bears in the institutional theory) becomes easier to achieve abroad managers will resort to the efficiency criteria (which bears in the transaction costs theory) in order to draw their entry strategies in the foreign market. The somehow ambiguous results presented by the literature regarding the effects of institutional distance on equity ownership choices might be better explained when considering the level of institutional development of the host country. The level of institutional development in the host country directly affects MNEs strategic decisionmaking (Meyer, Estrin, Bhaumik \& Peng, 2009; Ando, 2012).

Institutional development in the host country sets the direction of the CBA regarding how difficult it can be achieving legitimacy abroad. Institutional development can be seen as a coordination mechanism fostering uncertainty reduction (Meyer, 2001), providing meaning and setting behavior boundaries (Peng et al., 2009), and making it easier to achieve legitimacy in the host country. Peng (2003) explains that, in a given economy, as complexity increases - regarding scale, scope and specificity - more complex transactions and more transaction parties emerge as well. In this instance, regulatory institutional development looms to help economic agents coping easily with the environment idiosyncrasies. The author also highlights that these mechanisms do not occur always in the same direction. If institutionally the regulatory environment seems to be inadequate to fulfill the economic needs then the economic agents will resort to more informal relationships in order to pursue their business activities. MNEs will pursue personal or impersonal relationships abroad according to their own legitimacy needs (Peng, 2003).

Overall, research evidences that institutions condition MNEs' strategic options. Particularly, the degree of ownership chosen by MNEs is strategic because it bounds how the parent firm controls its resource base, exerts authority, promotes organizational changes, implements new processes, deals with connections in local context, and learns to adjust to unfamiliar political and legal (Elango et al., 2013; Li, Peng \& Macaulay, 2013), economic and cultural (Rugman et al., 2011) environments. 


\subsection{Institutional differences across countries}

Institutional distance and the level of the host country institutional development differ and interact. Institutional distance affects MNEs' ability to achieve legitimacy abroad by hampering MNEs' efforts to understand the foreign market (Kostova \& Zaheer, 1999; Kostova et al., 2008). This difficulty will likely trigger local conflicting reactions which may jeopardize MNEs' endeavors for both internal legitimacy (hindering subsidiary integration processes with parent firm such as the transfer of strategic routines) and external legitimacy (Kostova \& Zaheer, 1999; Xu \& Shenkar, 2002). However, regardless of managers' institutional distance perceptions, the host country might provide a given set of conditions that may make it easier or hinder the acceptance of MNEs operations by the foreign constituencies.

Research suggests two distinct and complementary approaches (Hernández \& Nieto, 2015) to explain why the level of the host country institutional development interacts with the institutional distance perceptions when MNEs are drawing their international business strategies: (1) the transaction cost approach (Meyer, 2001); and (2) the strategic-legitimacy approach (Suchman, 1995). First, within the transaction cost approach, the existence of institutional voids - such as unclear regulatory frameworks, inexperienced bureaucracies, underdeveloped court systems, and institutional settings with corruption issues and weak property rights protection - increase transaction costs (Meyer, 2001; Chan et al., 2008; Abotsi \& Iyavarakul, 2015). Hence, "institutional development affects entry mode choice as underdeveloped institutions drive the costs of establishing wholly-owned ventures" (Meyer, 2001, p. 365), regardless of institutional distance considerations. Institutional distance and institutional voids combine to inhibit MNEs from gaining legitimacy in the host country.

Second, by the strategic-legitimacy approach, legitimacy can be depicted as an operational resource (Suchman, 1995) because MNEs may emerge themselves as their own legitimacy builder actors by manipulating environmental structures, and creating their own audiences and legitimacy beliefs through negotiations based in a dynamic that often bears on power relationships (Kostova, Roth \& Dacin, 2008). When facing their institutional strategic choices to achieve legitimacy abroad MNEs may choose for compliance, cooptation or defiance attitudes (Peng, 2003) and these considerations likely have some degree of freedom in relation with the institutional distance analysis. Kostova and Zaheer (1999, p. 65) state that "it is possible for an MNE to be culturally adapted and still lack legitimacy in a particular environment", which outlines that there 
may not be a full correspondence between overcoming institutional distance and achieving legitimacy.

The literature recognizes the influence of the normative and cognitive dimensions in the regulatory framework of any host country, which adds an additional element of complexity for understanding the encounter between entities coming from disparate origins. Countries that share the same language and the same religion often share institutional structures and business practices (Kedia \& Bilgili, 2015). By the same token, when two countries share historical ties, either positive or negative, citizens possess greater knowledge of local laws and business practices (Kedia \& Bilgili, 2015). France is an example of such instances since the country maintains "special relationships with former French colonies in Africa" which confers special trade access and a sense of proximity between countries (Brewer, 2007, p. 51). Even when that historical ties lead to increasing animosity between two countries, still that probably mean that home and host country's citizens realize each other better compared with some other distant countries. This focus on what might bring cultures together (Shenkar, 2001) helps understanding the perceptual nature of cross-country distances (Sousa \& Lages, 2011) and, therefore, contributes to enhance our knowledge over MNEs entry mode choices.

Knowledge differences across countries can also present another source of difficulties preventing MNEs from obtaining legitimacy. Berry et al. (2010) argue that assessing knowledge distance is important because proximity to knowledge influences firms' location choices, while talent, innovation, and creativity vary across countries. Knowledge and innovation seem to be the two sides of the same coin. The numbers of patents and scientific articles by country have been used by the literature on national innovation systems to assess cross-national distances (Berry et al., 2010). Knowledge emerges as one determinant of the nature of business competition (Lu, Tsang \& Peng, 2008) thus constraining firms' competitive advantage effectiveness. By sensing knowledge distance managers might perceive differences in infrastructure and factor market between home and host countries, which can be crucial for "adapting, integrating and reconfiguring internal and external organizational skills, resources and functional competences to match the requirements of a changing environment" (Teece, Pisano \& Shuen, 1997, p. 515). Knowledge distance can increase the uncertainty MNEs are dealing with when engaging in a CBA. For example, cross-country differences in labor skills may represent increasing operational costs due to renewed employees' 
training needs, which may also raise resistances hampering the process of integration between the parent firm and the subsidiary. Knowledge distance inhibits obtaining both internal legitimacy and external legitimacy (Lu et al., 2008; Meyer et al., 2014).

\subsection{Gaining legitimacy in foreign countries}

Differences between home and host countries institutional environments forces MNEs to assess the requirements demanded by host country's agents to be considered a legitimate player. The heterogeneity of firm origins and capabilities leads host country's main actors to rely on prior experiences, common standards and stereotypes to build their expectations upon the foreign firm engaging in a CBA (Kostova \& Zaheer, 1999). The encounter between home and host entities depends upon mutual perceptions, which likely evolve and change with the increasing interactions between the parties (Shenkar, 2001), and allows MNEs to adapt strategies for gaining legitimacy abroad.

The interactions between individuals, such as MNEs' managers and host country's government officials, influences MNEs strategies for obtaining legitimacy abroad and does not have necessarily to be exclusively dependent on cross-country differences. Escaping from the idea of "distance", Shenkar, Luo and Yeheskel (2008, p. 918) propose a "friction perspective" which calls attention to the actual contact between parties, "including its power and interest asymmetry", and points out that overcoming environmental uncertainty depends upon how each participant understands and reacts to the interactions between them.

Understanding the institutional effects on the ownership in CBAs requires a combined focus on both cross-country distances and host country requirements for granting legitimacy. The scope of cross-country distance embraces several dimensions (Berry et al., 2010). However, the influence that each of these dimensions exerts over MNEs ability to achieve legitimacy is quite disparate according to the relevant institutional context which, for instance, can be conditioned by the existence of trade agreements between countries (Brewer, 2007). Furthermore, the absence of legitimacy in an host country does not mean outright rejection and the results from the collision between the MNE and the legitimating actors abroad is dependent upon their mutual perceptions and interactions (Shenkar et al., 2008). Cross-national distance and legitimacy are two theoretical concepts important for MNEs when setting up their international business strategies. While both concepts relate to the firm needs to cope 
with the uncertainties presented by the international business environment, research outlines important distinctions between these constructs that deserve to be mentioned.

Psychic distance is a concept that has been widely studied and accepted as having impact for adequate market selection, entry mode choice (Johanson \& Vahlne, 1977; Dow \& Karunaratna, 2006; Brewer, 2007; Håkanson \& Ambos, 2010), and suitable MNEs management strategies as well (Swoboda, Elsner \& Olejnik, 2015; Rugman et al., 2011; Risberg, 2003). The concept comprehends the "factors that make it difficult to understand foreign environments" (Johanson \& Vahlne, 2009, p. 1412) such as "differences in language, education, business practices, culture and industrial development" (Johanson \& Vahlne 1977, p. 24). Hence, "psychic distance" is a multidimensional construct challenging researchers over a widespread range of questions regarding how to apply it for enhancing international business understanding. The concept embraces the perception of geographic, cultural and institutional differences between home and foreign markets (Brewer, 2007), and comprehends country characteristics and people characteristics as well (Sousa \& Lages, 2011; Dow \& Karunaratna, 2006). As described in the Uppsala model (Johanson \& WiedersheimPaul, 1975; Johanson \& Vahlne, 1977) managers' perception of distance between countries accounts for hurdling knowledge flows and explains that difficult to get known markets are avoided ones (Brewer, 2007). This deterrent effect of institutional distance (Dow \& Ferencikova, 2010) highlights that manager familiarity with the markets is a key element since managers "must intellectually understand and emotionally relate to conditions in foreign countries" (Håkanson \& Ambos, 2010, p. 198).

Legitimacy, in turn, refers to where MNE's actions and activities are seen as acceptable, proper and appropriate within the host countries environments (Human \& Provan, 2000; Kostova \& Zaheer, 1999), and within the multinational structure (Kostova et al., 2008; Kostova \& Zaheer, 1999). When entering foreign markets both the MNE and the host country legitimating actors lack information about each other (Chari \& Chang, 2009). This information asymmetry needs to be overcome at least as close as possible to the point where MNE's actions and activities in the host country are allowed to pursue in a regular basis. The higher the information asymmetry between the MNE and its legitimating actors, the more the host country environment resorts to stereotypes and its own standards in judging MNEs behavior (Kostova \& Zaheer, 1999). 
The host country often exhibits a bundle of social pressures over the MNEs legitimacy granting process.

The literature highlights that MNEs need being able to identify the host country's legitimating main actors in order to be successful. This capability enables firms to grab opportunities abroad spite the presence of some institutional distant factors, while avoiding low return-high risk country settings (Chan et al., 2008; Li et al., 2014). Chan et al. (2008), studying Japanese foreign affiliate performance in 38 host countries between 1996 and 2001, identify Indonesia, Thailand and China as countries with low return-high risk profile within the considered period. Regarding the institutional pressures firms face when engaging in international business ventures, Li et al. (2013) outline the example of Royal Dutch Shell entering Eastern Russia through obtaining a $55 \%$ stake in the Sakhalin oil fields without duly safeguarding the risks involved in the operation. Later on, due to its inability to manage the relationships with the government and other local stakeholders, the company was forced to abandon its investment by selling its shares under market prices (Li et al., 2013). To be successful, MNEs need to identify the host country's legitimating constituencies for assessing the appropriate ownership strategy. 
(This page was intentionally left blank) 


\section{Hypotheses}

African countries present a very idiosyncratic institutional context influencing AfMNEs' ownership strategies across borders. Legitimacy challenges faced by AfMNEs engaged in a CBA seem to be exacerbated by their home underdeveloped institutional environments. Particularly, regarding the regulatory and technological distances to host countries in advanced economies (Meyer et al., 2014), AfMNEs' ownership choices might act as an important tool to successfully overcome these legitimacy challenges.

AfMNEs face several administrative idiosyncrasies that may raise difficulties for achieving legitimacy abroad. Africa is a very special continent regarding ethnic and linguistic variety, which acts as a source of separation between cultures. Before the colonial era up to ten thousand different autonomous groups were living by their own customs; and today over two thousand recognized languages still remain actively spoken (George, Corbishley, Haas \& Tihanyi, 2016). Therefore, disparate tribal identities and cultures create accrued difficulties for any effort of formal institutional building, and distrust is often present among the members of an African organization. George et al. (2016) refer that MNEs need to deal effectively within "communities of place" and adopt regional "lingua francas" such, as Swahili, in order to establish local legitimacy. Moreover, the variety of legal influences the continent has received from the colonial countries, such as British common law and French civil law, sets a potential of heterogeneous legal frameworks among the African countries. Thus, even when performing a CBA inside Africa it is likely that AfMNEs are still facing administrative distant environments.

Also, Africa is a continent at a huge disadvantage on technology and know-how issues compared to worldwide developed countries. In general, Africa unbalances regarding technology and know-how considerations can be illustrated as follows: the continent lacks human capital due to paucity in educated people, only $2 \%$ of academic research authors are in Africa, and 70\% of all top-ranked African enterprises by turnover and profits are originating from South Africa (George et al., 2016). With the possible exception of South Africa enterprises, this reality prompts a huge distance between AfMNEs' home countries and the large majority of the developed countries 
where a potential CBA can be engaged by an African firm. AfMNEs' managers may lack educational training to compete globally (Hoskisson, Wright, Filatotchev \& Peng, 2013) and the firms may lack absorptive capacity to deal effectively with the new information and know-how they may be gathering. Weigelt and Miller (2013) state that the multiplicity of knowledge sets and their interrelatedness results in a task complexity that requires a given firm's internal infrastructure to properly manage the knowledge flows. Therefore, African countries are at a struggling position for competing with firms from advanced economies.

Although the recognized importance of institutional distances, not all institutional dimensions present the same relevance during a CBA process. An in depth analysis of these two cross-country distances - administrative distance and knowledge distance seems to be more meaningful for understanding AfMNEs efforts to achieve legitimacy abroad than looking at other dimensions, such as economic distance, political distance or financial distance. The literature outlines that these two cross-country distances usually raise the first barriers for an MNE that wishes to gain legitimacy abroad (Xu \& Shenkar, 2002; Meyer et al., 2014). The regulative distance is the most relevant dimension in the initial phase of the international expansion because it sets the "rules of the game" and constraints the firm resources that can be unfold in the host country (Xu \& Shenkar, 2002). In developed host countries and within the acquired companies, knowledge distance might raise fears of losing critical technologies and know-how to foreign competition, a sentiment that might be exacerbated when the acquirer comes from an underdeveloped economy (Meyer et al., 2014). Hence, AfMNEs' ownership strategies may be primarily driven by considerations over cross-country distances regarding the administrative and knowledge dimensions.

\subsection{Administrative distance}

Specifically, administrative distance, as defined by Berry et al. (2010), encompasses cross-country differences in legal systems and language, while also accounting for the existence of colonial ties between them. The administrative dimension goes beyond the formal institutional arrangement provided by the legal framework to include the informal influence of normative and cognitive social structures when setting the rule of law of a given country (Berry et al., 2010).

Because the administrative dimension, as measured by Berry et al. (2010), encompasses differences in the legal framework between home and host countries, it 
can be an important source of uncertainty for the MNE. Legal system contingencies impact MNEs organizations capabilities and strategically positioning operations because managers' perceptions of host country's ex ante commercial law inadequacy and ex post judicial arbitrariness both impact MNEs' political ties intensity in the foreign country (White III, Boddewyn \& Galang, 2015). In other words, MNEs' needs for non-market capabilities to effectively gather legitimacy in the host country through ties with the government, government officials or other local entities (such as trade associations, unions and local firms) depend upon managerial perceptions of the foreign legal system regarding the adequacy of the laws and the quality of its enforcement. The relevance of this institutional dimension lies in its potential for increasing the uncertainty MNEs must cope with while conditioning how MNEs adapt to the international business environment.

Africa presents an interesting institutional context when considering Berry et al. (2010) administrative dimension. Since the XV century and until the XX century, apart Liberia and Ethiopia, the whole African continent was colonized. This huge colonization was mainly dominated by France and Great Britain, but other countries, such as Germany, Portugal, Belgium, Spain and Italy also had their colonies in Africa. Administrative distance refers primarily to differences between countries' legal systems, and comprehends common language and the existence of colonial ties as well (Berry et al., 2010). According to La Porta, Lopez-de-Silanes, Shleifer and Vishny (1998), generally, existing commercial laws are rooted in two main origins: the common law, which is British rooted, and the civil law, which is originated in Roman law and is actually close to the French and German civil traditions. Hence, due to the existence of multiple colonial ties and different legal framework influences, it is expectable that within the African continent each country administrative institutional measure often varies. Hence, cross-country administrative distance poses legitimacy hurdles which, in turn, might influence AfMNEs ownership strategies.

Regarding the perceived administrative distance between home and host countries, AfMNEs strategic choice for full or partial ownership when performing a CBA seems to be dependent upon firms' nonmarket capabilities and how these capabilities might be effective in the host country. Absence of historical ties in conjunction with differences in legal frameworks and language magnifies uncertainty, either by hindering understanding over the existing regulatory framework (Tykvová \& Shertler, 2014) or through hampering perceptions over direction and frequency of 
possible future institutional changes (Meyer, 2001). While the former might preclude the transfer of knowledge and routines between the parent firm and its subsidiary (Xu \& Shenkar, 2002; Meyer, 2001; Kostova \& Zaheer, 1999), inhibiting MNEs efficacy abroad, the latter highlights the need to identify the most relevant legitimating actors in the host country in order to achieve and maintain legitimacy (De Villa et al., 2015), and safeguard against private and public expropriation hazards that may arise (Delios \& Henisz, 2000), thus demanding non-market capabilities.

The preference for a partial ownership in administrative distant countries seems to be adequate for achieving two purposes: the management of operational risk and the management of legitimacy in the host country. By sharing risks with a local partner AfMNEs might get access to local tacit knowledge with reduced transaction costs (Ando, 2012). Likewise, Dikova (2009, p. 46) states that " a joint operation with a local partner might be a "substitute" for own market experience". Also, by partnering with a local firm MNEs also may shield themselves against foreign government threats such as shifts in industry and tax policies or "outright expropriation of private sector assets" (Delios \& Henisz, 2000, p. 307), while undertaking effective political strategies (Li et al., 2013), managing environmental uncertainties and improving firm performance (Li, Chen, Liu \& Peng, 2014). Furthermore, partnerships might be helpful to mitigate the institutional distance effects due to cross-country differences regarding issues such as environmental protection and social responsibility ( $\mathrm{Lu}$ et al., 2008). In hypothesizing from the above mentioned I propose that:

Hypothesis 1: Greater administrative distance between the acquirer's African home country and the target is negatively related to the ownership in CBAs, such that AfMNEs are more likely to seek a partial ownership as home-host administrative distance increases.

\subsection{Knowledge distance}

There are several reasons pointed out by the literature for MNEs from emerging economies to enter host countries in high developed institutional settings, each one posing specific obstacles for obtaining legitimacy. Some of those reasons are as follows: overcoming their home countries institutional limitations; gaining access to new technologies and know-how; accessing new markets; accessing new distribution channels; and seeking free rides in well-established brand images (Delios \& Henisz, 2000; Peng, 2012; Osabutey, Williams \& Debrah, 2014; Hernández \& Nieto, 2015; 
Lebedev, Peng, Xie \& Stevens, 2015). Most of these reasons encompass a strategic asset seeking motive aiming at the enhancement of the firm's competitive advantage at home or within a third-country market (Meyer, 2015). Knowledge distance refers to the differences between talent, innovation, creativity and capacity to create knowledge (Berry et al., 2010). Specifically in what concerns to cross-country knowledge distance, due to the technological leakage threat that it can be associated with, these reasons might hinder AfMNEs' achievement of legitimacy abroad (Meyer et al., 2014).

Ownership strategies help MNEs deal with the legitimacy problems posed by knowledge distance issues. The literature suggests that networks are conducive to innovation (Chen et al., 2012) and that "tacit knowledge is regarded as more important for innovation" (Lu et al., 2008, p. 362). Knowledge transfer and innovation capabilities seem to require interaction and team work between foreign firms and local ones (Osabutey et al., 2014). Hence, managers perceived cross-country knowledge distance impacts AfMNEs decisions regarding the CBA equity composition because it may affect decisively either the access of the firm to technology and know-how or the firm's ability to transfer its knowledge based products, processes and routines to, or from, its subsidiary.

MNEs need to carefully assess the institutional environment in order to understand the potential impact of knowledge distances in their ability to manage legitimacy when engaging in a CBA. Knowledge-based resources are environmental dependent, being particularly useful for improving firm performance in changing and unpredictable environments (Miller \& Shamsie, 1996). The environmental context conditions the value of a knowledge-based resource at least in two ways. First, knowledge-based resources involve a multiplicity of skills and talents from different sources - including technical, creative and collaborative skills - that once interrelated (Weigelt \& Miller, 2013) will enable the firms to adapt their product to market needs and challenges (Miller \& Shamsie, 1996). Second, knowledge can be "denied if it is perceived to be in contradiction with existing social norms or to raise a challenge to current institutional rules" (Lu et al., 2008, p. 366). This institutional constraint applies in several moments of knowledge manipulation such as its creation, transmission, imitation or relocation (Lu et al., 2008). Hence, cross-country knowledge distance can be troublesome either by posing perceptional issues regarding foreign market understanding or hindering firms' ability to achieve legitimacy. 
Moreover, the protection of technology transferred between home and host countries as well as the scope of patent protection and copyright vary across countries (Ang, Benischke \& Doh, 2015) adding another source of uncertainty. Home and host governments may also enhance or inhibit MNEs perceived uncertainty regarding knowledge distance issues through tax incentives or other specific policies fostering technological development (Chen, Li \& Shapiro, 2012), posing an additional challenge for the management of legitimacy in the foreign country.

Africa is lagging world developed countries on technology and know-how issues, either on tacit or codified knowledge, suggesting that the preference for a partial ownership in knowledge distant countries seems to be adequate for achieving several purposes: as a facilitator for the transfer of innovation and know-how which is often tacit in nature; as a facilitator to adequate product, processes and routines to market needs; and as a facilitator for the management of legitimacy in the host country. Lu et al. (2008) state that relational arrangements between organizations, such as partnerships, strategic alliances, and networks, favor knowledge transfer and imitation. Further Kogut and Singh (1988, p. 412) argued that "joint ventures are not merely a matter of equity control, but represent a set of governance characteristics appropriate for certain strategic or transaction cost motivations or for the transfer of tacit organizational knowledge", setting the ownership structure decision as a "vehicle by which to share complementary but distinct knowledge which could not otherwise be shared or to coordinate a limited set of activities to influence the competitive positioning of the firm". Accordingly, I hypothesize:

Hypothesis 2: Greater knowledge distance between the acquirer's African home country and the target is negatively related to the ownership in CBAs, such that AfMNEs are more likely to seek a partial ownership as home-host country knowledge distance increases.

\subsection{Target institutional development}

The level of the host country institutional development influences MNEs establishment mode choices (Chen, Cui, Li \& Rolfe, 2016; Dikova \& Brothers, 2016). Leastwise, research suggests that there are two different strategic perspectives through which managers must look at the level of the host country institutional development because it has different effects on MNEs legitimacy 
First, the level of the target country institutional development influences MNEs' resource-based strategies for rent generation and legitimating strategies (Chan et al., 2008; Miller \& Shamsie, 1996). If the MNE is aiming at targets in institutionally higher developed host countries it is likely that firm specific market resources and capabilities become more relevant. In this case, the firm is facing a more stable, credible and market supporting institutional environment (Peng, 2002, 2003; Lin, Peng, Yang \& Sun, 2009; Hoskisson et al., 2013; Hernández \& Nieto, 2015) requiring less personal relationships for achieving legitimacy abroad. Institutional pressures for conformity are widely spread over the competing firms (Xu \& Shenkar, 2002; Dacin, 1997) thus MNEs cannot expect to have a large wiggle room for significantly improve their competitive advantage and legitimacy achievement through the use of nonmarket capabilities (Chan et al., 2008). In this instance, Miller and Shamsie (1996) show that property-based resources acquire more relevance for firms' performance in more stable environments. Conversely, if a firm is entering institutionally less developed host countries then knowledge-based resources gain preponderance (Miller \& Shamsie, 1996) and nonmarket capabilities loom as crucial to firms success as well (Peng et al., 2009; Li et al., 2014; Estrin et al, 2016). The level of the host country institutional development impacts the firm's ability to generate returns from its investment and the appropriate strategies for gaining legitimacy abroad (Shenkar et al, 2008).

Second, target institutional development decisively impacts the costs of doing business abroad (Chan et al., 2008; Meyer, 2001) influencing MNEs' risk management strategies. Weak institutional environments are characterized by government arbitrariness (Aybar \& Ficici, 2009), inadequacy of legal environment and tenuous law enforcement (White III et al., 2015), which lead to the rising role of normative and cognitive institutional pillars in regulating the interactions between economic agents (Peng, 2002, 2003; Peng et al., 2009). In these instances, transaction costs importance magnifies because the absence of market-supporting regulations inhibits the establishment of efficient negotiations, bureaucracies are often exacerbated, and the orientation of government policies often lacks both consistency and credibility (Murtha \& Lenway, 1994). Thus, the amount of uncertainty present in this environment demands MNEs to develop nonmarket capabilities in order to manage legitimacy, while trying to keep as low as possible the operational costs of doing business. Also, in these environments, gaining, maintaining and repairing legitimacy require specific dynamics that are different from the ones needed to succeed in developed institutional settings 
(Suchman, 1995). Consequently, the level of the host country institutional development strongly influences the MNEs ownership choices when pursuing a CBA.

According to $\mathrm{Xu}$ and Shenkar (2002), when engaging in international business endeavors, small integration costs lead MNEs to opt for majority stakes. The literature confirms the above mentioned arguments favoring the existence of a positive relationship between the level of the host country institutional development and the preference for full ownership (Hernández \& Nieto, 2015; De Beule et al., 2014; Chan et al., 2008; Ando, 2012; Harzing, 2002; Meyer, 2001; Delios \& Henisz, 2000; Khanna \& Palepu, 2000). Nonetheless, Elango and Pattnaik (2011, p. 465) point out two more potential factors favoring AfMNEs' entrance into institutionally high developed host countries through a full ownership acquisition. First, acquirers coming from less developed economies "lack critical capabilities to operate locally" in developed host markets. Therefore, by acquiring a target firm in the developed host country the MNE overcomes entry barriers and get access to those capabilities the firm is aiming at. Second, since the MNE likely does not bring much to a partnership with a local firm in the institutionally developed host country it is doubtful that there are firms "willing to partner with emerging market firms to help them on their home turf" (Elango \& Pattnaik, 2011, p. 467). Thus, I hypothesize that:

Hypothesis 3: Greater host country institutional development is positively related to the ownership in CBAs, such that AfMNEs are more likely to seek full ownership in more institutionally developed target countries.

I further propose that the analysis of the MNE institutional context needs to include both the institutional distance considerations and the analysis of the level of institutional development of the host country. Chan at al. (2008, p. 1180) defined the level of institutional development as "the extent to which the economic, political, and social institutions in a host country are developed and are favorable to foreign affiliates". For instance, legitimacy has a role preventing hostility and conflict situations, while behaviors towards xenophobia, ethnicity or national sovereignty, often help defining a geopolitical context (Shenkar et al., 2008). Those may not easily be captured only through the analysis of institutional distance when one strives for sensing how to obtain legitimacy abroad. The institutional environment is important for international business strategy because it is a key determinant of firm structure and 
behavior (Xu \& Shenkar, 2002). Therefore MNEs will likely enhance their capabilities to compete abroad by considering in tandem the institutional distance and the level of institutional development of the host country.

The most subtle although important difference between the concepts of institutional distance and legitimacy lies in the direction of the analysis regarding the goal of overcoming uncertainty. Within the institutional distance concept, the main actor trying to overcome uncertainty is the firm. Managers' capabilities for understanding host country market conditions determine how distant the foreign market is perceived (Brewer, 2007; Dikova, 2009; Sousa \& Lages, 2011), thus conditioning the firm's international business strategies. Consequently, under the institutional distance rationale, the efforts to overcome uncertainty are MNE centered. Within the legitimacy concept, the acceptance of MNEs operations as desirable, proper, and adequate depends on foreign constituencies (Kostova et al., 2008; Suchman, 1995), prompting that the efforts to overcome uncertainty are now centered in the host country main actors. In other words, while the institutional distance concept relates to the efforts of a MNE for overcoming the inherent risks of engaging in international business activities, the concept of legitimacy rests in host country's legitimate constituencies evaluating the uncertainties and possible consequences carried out by the deployment of MNE's activities in their territory.

While institutional distance buttresses its analysis tools from upstream to downstream, the achievement of host country legitimacy also requires an analysis from downstream to upstream. The former tries to answer the question "what do we know about the host country market conditions in order to do business successfully" while the latter seeks to know "what should we accomplish in order to be accepted in the host country". To succeed, MNEs need to both adapt to the international business environment and overcome the lack of knowledge about market conditions abroad (Ferreira, Serra \& Reis, 2011). Therefore, because of their implications over the scope of uncertainty the acquirer firm is faced with, integrating the two concepts enhances our understanding over the appropriate strategies to be delineated by MNEs when engaging in their international endeavors.

Since strong or weak host country institutional environments do not have "the same limiting role when firms seek legitimacy" (Hernández \& Nieto, 2015, p. 124), then the level of institutional development of the host country should act as a moderator of the cross-country distance effect over AfMNEs ownership stake choices in their CBAs. 
Considering institutional effects, the literature provides two interesting studies that enhance our understanding over MNEs' ownership strategic choices.

First, Brouthers and Brouthers (2001, p. 178) explained that "an apparent paradox exists with respect to the relationship between cultural distance and entry mode choice". Drawing over a similar perception of distance, the authors identify two separate theoretical guidelines for the chosen ownership: (1) one consisting of several studies where partial ownership choices were taken as appropriate for increasing firm flexibility dealing with the risks abroad, while simultaneously accessing local knowledge; and (2) another set of studies where full ownership choices were considered beneficial for providing reduction in integration costs, enhancing control over the venture and protecting the MNE against partner opportunistic behavior. In their study, Brouthers and Brouthers (2001) outline that host country risk is a moderator of the perceived distance effect. The authors measured country risk as the perceived stability of the social, economic and political environment; considered a sample of firms from developed economies entering emerging markets; and found that, when facing cultural distant and high investment risk countries, MNEs prefer higher ownership. In this instance, MNEs increase their ownership position to better manage the risks involved. The choice of ownership is thus, at least in part, driven by control considerations.

Second, Chan et al. (2008), considering a sample of Japanese home firms and investigating the effect of the level of the host country institutional development in their subsidiaries performance conclude that the performance of the subsidiaries can be low in either settings, in institutionally developed or in underdeveloped host countries. However, these authors did find that the variation of the subsidiaries performance was quite higher in institutionally less developed host countries, increasing the prospects for profit potential at higher uncertainty. They have found out as well that advanced economies (such as United States, France, Germany, United Kingdom and Italy) fell into the low risk-low return category. To disentangle the combined institutional effects coming from cross-national distance and legitimacy issues MNEs need to consider their generating rent ability within the inherent risk framework.

According to the Uppsala model (Johanson \& Wiedersheim-Paul, 1975; Johanson $\&$ Vahlne, 1977) firms are naturally risk averse. The model presumes that MNEs will enter foreign markets with low commitment entry modes and gradually increase their commitment as long as their familiarity with host countries becomes higher. Therefore, in this model, higher ownership levels will be sought when the perceived investment 
risk is lower. However, empirically, research did not always support the model, which leaded to the cultural distance paradox. Nonetheless, all else equal, the assumption that firms have a negative stance towards risk must be considered since firms would not be willing to accept more risk in their investment without a substantial increase in the potential profit. Thus, when AfMNEs are entering more institutionally developed countries through a CBA, they will probably be facing less uncertainty due to easiness in obtaining legitimacy while simultaneously increasing their prospects for future profits at home. Thus, in this case where the risks are lower and legitimacy easier to achieve, higher ownership stakes seem to be more adequate, allowing AfMNEs to fully capitalize the investment abroad.

Conversely, when entering institutionally underdeveloped settings, AfMNEs will be facing environments were legitimacy is more difficult to achieve. Therefore, the increase in uncertainty due to legitimacy difficulties coupled with cross-country differences issues inhibits the AfMNE to take full advantage of the host market potential and, consequently, will likely lead the AfMNE to look for a partnership. The partnership is preferable if it provides a reduction in the uncertainty AfMNEs is going to face abroad concerning its legitimacy achievement in the host country, while simultaneously improving the firm's ability to increase its investment profit potential by capturing opportunities ( $\mathrm{Li}$ et al., 2014).

Research confirms that institutionally higher developed countries will lead MNEs to prefer higher commitment entry modes (Hernández \& Nieto, 2015; De Beule et al., 2014; Meyer et al., 2009) and that less developed institutions increase the perception of the difficulties to properly manage regulative distance (Håkanson \& Ambos, 2010). Therefore, regarding the expected moderating action of the level of the host country institutional development over the effect on ownership by administrative distance, I propose the following:

Hypothesis 4: The level of institutional development of the host country moderates the relationship between administrative distance and the choice of ownership, such that the effects of administrative distance on the ownership are weaker when the institutional development of the host country is higher.

The hypotheses presented above are represented in Figure 1. 
Figure 1. Conceptual model

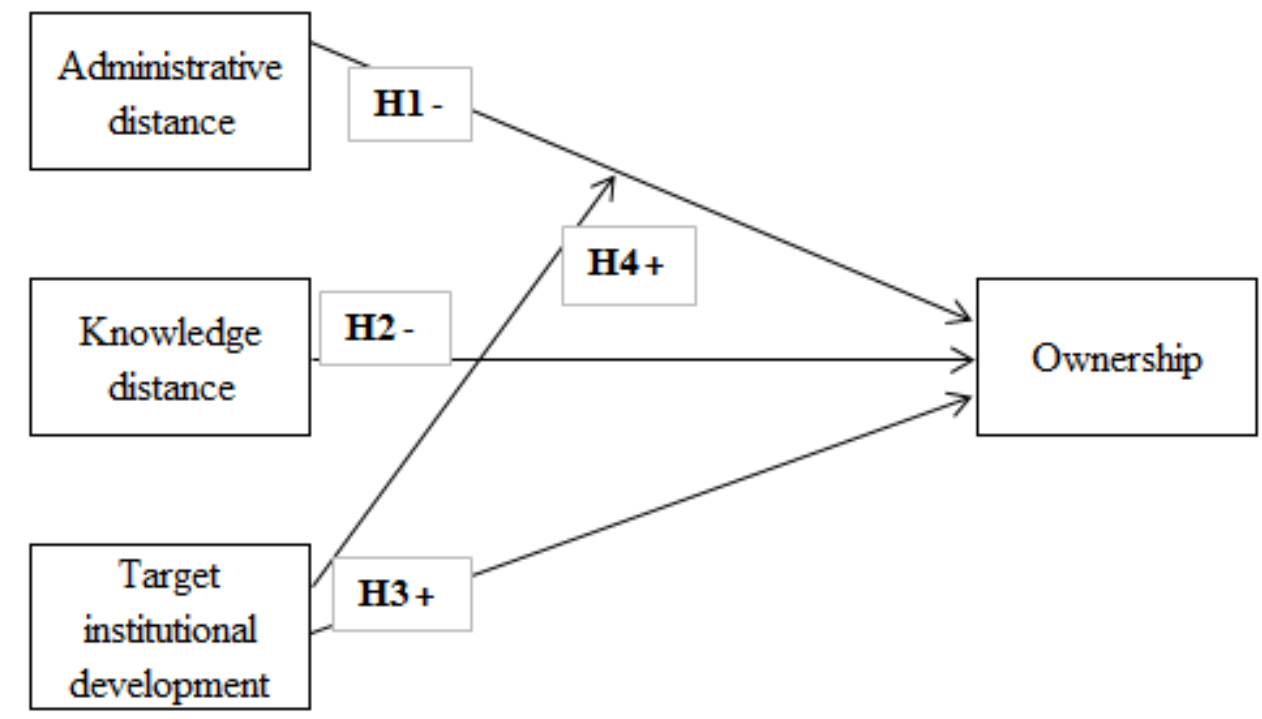




\section{Method}

\subsection{Data and sample}

This study uses a sample of CBAs made by AfMNEs from 1985 to 2015. The data on CBAs were obtained from the Worldwide Mergers and Acquisitions database (SDC Platinum) prepared by Thomson Financial Securities. This database has been widely used for international business research (e.g., Aybar \& Ficici, 2009; Elango et al., 2013).

In selecting the sample I have followed a number of procedures. First, I have considered only those CBAs that were "completed", thus excluding those that were not yet completed until the final day of the dataset, and those that were classified as rumors. Second, only initial operations were considered to avoid biases due to the existence of previous knowledge and experience related to the specifics of the transaction. Third, following prior research, I only included CBAs for which the acquirer firm was acquiring an ownership stake equal or greater than $10 \%$ of the target's equity (Dikova, 2009). Albeit the literature is not consensual in establishing a cut-off point, the rationale is that a too small ownership stake - such as $5 \%$, for instance - may be revealing a portfolio investment, aimed at speculative investments. Fourth, I only considered CBAs in which the acquirer firm was based in an African country. Fifth, I excluded cases where the CBA involved an acquisition in an offshore and also those instances involving firms from the islands of Reunion (as home country) and Isle of Man (as host country). Both islands are dependencies of other sovereign countries, namely, France and United Kingdom. These procedures resulted in a total of 942 CBAs made by AfMNEs during the thirty year period, from 1985 to 2015.

Specifically, I have chosen to test the hypotheses by analyzing the last seven years of the database, from 2009 to 2015, which allows for obtaining experience measures from previous years, between 1985 and 2008. Table 1 describes the final database which consists of 314 CBA's made by AfMNEs, from 24 home countries in 71 host countries. Following, Table 2 describes the sample by percentage of ownership acquired. 
Table 1. Number of acquisitions by country: 2009 to 2015

\begin{tabular}{|c|c|c|c|c|c|c|c|}
\hline & $\begin{array}{c}\text { World } \\
\text { Total }\end{array}$ & $\begin{array}{c}\text { In } \\
\text { Africa }\end{array}$ & $\begin{array}{l}\text { Out of } \\
\text { Africa }\end{array}$ & Europe & NAFTA & $\begin{array}{c}\text { Central } \\
\text { and } \\
\text { South } \\
\text { America }\end{array}$ & $\begin{array}{c}\text { Asia, } \\
\text { Middle } \\
\text { East } \\
\text { and } \\
\text { Oceania }\end{array}$ \\
\hline Home countries & 314 & 130 & 184 & 97 & 26 & 8 & 53 \\
\hline Algeria & 5 & 0 & 5 & 5 & 0 & 0 & 0 \\
\hline Angola & 4 & 0 & 4 & 1 & 0 & 2 & 1 \\
\hline Botswana & 6 & 5 & 1 & 0 & 1 & 0 & 0 \\
\hline Cameroon & 1 & 1 & 0 & 0 & 0 & 0 & 0 \\
\hline Dem Rep Congo & 1 & 0 & 1 & 0 & 1 & 0 & 0 \\
\hline Egypt & 29 & 5 & 24 & 10 & 5 & 0 & 9 \\
\hline Ethiopia & 1 & 1 & 0 & 0 & 0 & 0 & 0 \\
\hline Ghana & 2 & 1 & 1 & 1 & 0 & 0 & 0 \\
\hline Ivory Coast & 3 & 3 & 0 & 0 & 0 & 0 & 0 \\
\hline Kenya & 14 & 12 & 2 & 0 & 1 & 0 & 1 \\
\hline Libya & 3 & 1 & 2 & 1 & 1 & 0 & 0 \\
\hline Mali & 2 & 1 & 1 & 1 & 0 & 0 & 0 \\
\hline Morocco & 19 & 13 & 6 & 3 & 0 & 1 & 2 \\
\hline Namibia & 3 & 2 & 1 & 1 & 0 & 0 & 0 \\
\hline Nigeria & 20 & 11 & 9 & 6 & 2 & 0 & 1 \\
\hline Rep of Congo & 1 & 0 & 1 & 1 & 0 & 0 & 0 \\
\hline Rwanda & 1 & 0 & 1 & 0 & 1 & 0 & 0 \\
\hline South Africa & 184 & 65 & 119 & 63 & 13 & 5 & 38 \\
\hline Sudan & 1 & 0 & 1 & 0 & 0 & 0 & 1 \\
\hline Tanzania & 1 & 1 & 0 & 0 & 0 & 0 & 0 \\
\hline Togo & 3 & 3 & 0 & 0 & 0 & 0 & 0 \\
\hline Tunisia & 8 & 4 & 4 & 4 & 0 & 0 & 0 \\
\hline Zambia & 1 & 0 & 1 & 0 & 1 & 0 & 0 \\
\hline Zimbabwe & 1 & 1 & 0 & 0 & 0 & 0 & 0 \\
\hline
\end{tabular}

\begin{tabular}{|c|c|c|c|c|c|}
\hline Host countries & & Host countries & & Host countries & \\
\hline Angola & 2 & Italy & 2 & Rwanda & 4 \\
\hline Australia & 18 & Ivory Coast & 7 & Sao Tome & 1 \\
\hline Benin & 1 & Jordan & 1 & Saudi Arabia & 1 \\
\hline Bosnia & 1 & Kenya & 10 & Senegal & 2 \\
\hline Botswana & 7 & Lebanon & 2 & Singapore & 2 \\
\hline Brazil & 6 & Lithuania & 1 & Somalia & 1 \\
\hline Burkina Faso & 1 & Luxembourg & 1 & South Africa & 5 \\
\hline Cameroon & 1 & Malawi & 4 & South Korea & 3 \\
\hline Canada & 8 & Malaysia & 3 & Spain & 4 \\
\hline Chile & 2 & Mali & 1 & Sudan & 1 \\
\hline China & 5 & Mexico & 2 & Sweden & 1 \\
\hline Cyprus & 2 & Morocco & 2 & Switzerland & 1 \\
\hline Czech Republic & 3 & Mozambique & 6 & Syria & 2 \\
\hline Dem Rep Congo & 3 & Namibia & 4 & Tanzania & 6 \\
\hline Egypt & 2 & Netherlands & 4 & Togo & 2 \\
\hline Ethiopia & 4 & New Zealand & 2 & Tunisia & 1 \\
\hline France & 16 & Niger & 1 & Turkey & 1 \\
\hline Gabon & 1 & Nigeria & 18 & Uganda & 3 \\
\hline Gambia & 1 & Papua N Guinea & 1 & United Kingdom & 43 \\
\hline Germany & 6 & Poland & 3 & United States & 16 \\
\hline Ghana & 8 & Portugal & 3 & United Arab Emi & 5 \\
\hline India & 4 & Qatar & 1 & Zambia & 10 \\
\hline Indonesia & 2 & Rep of Congo & 2 & Zimbabwe & 8 \\
\hline Ireland Rep & 3 & Russian Fed & 3 & & \\
\hline
\end{tabular}

Source:

With data collected from SDC Platinum 
Table 2. Number of cases by percentage of ownership acquired

\begin{tabular}{|c|c|c|c|c|c|c|}
\hline & \multicolumn{2}{|c|}{ Acquisitions In Africa } & \multicolumn{2}{|c|}{ Acquisitions Out of Africa } & \multicolumn{2}{|c|}{ Total acquisitions } \\
\hline & Target is high-tech & $\begin{array}{l}\text { Target is not high- } \\
\text { tech }\end{array}$ & Target is high-tech & $\begin{array}{l}\text { Target is not high- } \\
\text { tech }\end{array}$ & Target is high-tech & $\begin{array}{l}\text { Target is not high- } \\
\text { tech }\end{array}$ \\
\hline Minority ownership & 5 & 28 & 5 & 29 & 10 & 57 \\
\hline Equal ownership & 0 & 2 & 0 & 5 & 0 & 7 \\
\hline Majority ownership & 4 & 38 & 6 & 19 & 10 & 57 \\
\hline Full ownership & 11 & 42 & 28 & 92 & 39 & 134 \\
\hline Total & 20 & 110 & 39 & 145 & 59 & 255 \\
\hline
\end{tabular}

\begin{tabular}{|c|c|c|c|c|c|c|}
\hline & Same industry * & Not same industry & Same industry * & Not same industry & Same industry * & Not same industry \\
\hline Minority ownership & 16 & 17 & 16 & 18 & 32 & 35 \\
\hline Equal ownership & 2 & 0 & 2 & 3 & 4 & 3 \\
\hline Majority ownership & 30 & 12 & 9 & 16 & 39 & 28 \\
\hline Full ownership & 41 & 12 & 67 & 53 & 108 & 65 \\
\hline Total & 89 & 41 & 94 & 90 & 183 & 131 \\
\hline
\end{tabular}

\begin{tabular}{|c|c|c|c|c|c|c|}
\hline & $\begin{array}{l}\text { Host more } \\
\text { developed }\end{array}$ & Host less developed & $\begin{array}{l}\text { Host more } \\
\text { developed }\end{array}$ & Host less developed & $\begin{array}{l}\text { Host more } \\
\text { developed }\end{array}$ & Host less developed \\
\hline Minority ownership & 4 & 29 & 32 & 2 & 36 & 30 \\
\hline Equal ownership & 0 & 2 & 4 & 1 & 4 & 3 \\
\hline Majority ownership & 8 & 34 & 24 & 1 & 32 & 35 \\
\hline Full ownership & 12 & 41 & 118 & 2 & 130 & 43 \\
\hline Total & 24 & 106 & 178 & 6 & 202 & 112 \\
\hline
\end{tabular}

* It is considered acquisition within the same industry if there is one case of similarity between acquirer and target firms at the 3 digit sic code level.

Source: Author's computations with data collected from SDC Platinum. 


\subsection{Variables}

The dependent variable is ownership. This study focuses on the relationship between AfMNEs faced institutional context and their ownership strategic choices when engaging in a CBA. It is important to mention that previous studies outline the high incidence of complete ownership as the MNEs' favorite choice (Chari \& Chang, 2009; De Beule et al., 2014). Full ownership seems to be meaningful because the level of control the acquirer firm is able to secure is quite different in a complete ownership scenario when compared to a partial ownership stake choice (Xu \& Shenkar, 2002; Chari \& Chang, 2009; Kedia \& Bilgili, 2015). Following extant research, I used a threshold of $95 \%$ of the target equity to qualify the operation as a full acquisition (e.g., Dikova, 2009; Elango et al., 2013). Consequently, the dependent variable, ownership, was measured as a dichotomous variable, using the data collected from SDC. Full acquisitions were coded " 1 " and partial acquisitions were coded " 0 ".

\section{Independent Variables}

The independent variable administrative distance captures the regulative differences between home and host countries, and encompasses country differences in legal systems, language, religion, and bureaucratic patterns due to colonial ties (Berry et al., 2010). Although the literature presents different measures, calculation methods and databases for calculating institutional distances between countries, I have used Berry et al. (2010) measure of administrative distance. This data is made publicly available online at http://lauder.wharton.upenn.edu/ciber/faculty_research .asp. I have used the Mahalanobis method for the calculation of administrative distance.

Using Mahalanobis as the method, instead of the perhaps more common Euclidean distances, is better suited for measuring country differences because of its procedural properties and the manner in which it handles the characterization of the variables used to measure those dissimilarities. For instance, "the variables that characterize countries tend to be very highly correlated with one another" and the Mahalanobis method is better than the Eucledian method to statistically deal with such specificity while meeting the five desirable properties that distance measures ought to exhibit: symmetry, non-negativity, identification, definiteness, and triangle inequality (Berry et al., 2010, p. 1469).

I have followed identical reasoning for knowledge distance. This variable captures country differences related to their capacity to create knowledge and innovate, and it 
might decisively impact the post-acquisition integration process (Risberg, 2003; Rugman et al., 2011) and the achievement of legitimacy abroad as well (Meyer et al., 2014). Data for this variable was also collected from Berry et al. (2010).

The independent variable target institutional development assessed the level of institutional development of the host country. This variable was computed with data from the Human Development Index as disclosed by the United Nations. Chan et al. (2008), for their study about the effect of the level of institutional development of the host country in foreign affiliate performance, built the Institutional Development Index (IDI). This index is a measure that aggregates 12 institutional variables in three institutional sectors as follows: (1) economic institutions - GDP per capita, economic conditions, distribution infrastructure, and financial resources; (2) political institutions intellectual property rights, political system, law and order, and bureaucracy quality; and (3) social institutions - justice, harassment and violence, corruption in government, and civil freedom. These authors found that their IDI was highly correlated with other institutional measures used worldwide. For instance, that the Human Development Index (HDI) had correlation coefficients with the IDI of about 0.8 between 1996 and 2001. Moreover, data on the HDI is available for every year of this study, thus allowing capturing possible improvements on the extent of institutional development of the countries. The HDI encompasses a life expectancy index, an education index, and a GDP index as well.

\section{Control variables}

I further included a number of control variables at the transaction, firm, industry and country level, as follows.

At the deal level I have controlled for the transaction value since deals involving greater financial disbursements could lead the acquirer to assume only a partial acquisition, or a lower ownership stake in the target. This variable thus controls for the potential effect of the value of the transaction in the AfMNEs' ownership stake choice. Data for this variable was collected directly from SDC and reported in millions of US dollars.

I controlled for the degree of diversification because research has shown that acquirer diversification levels may impact entry mode choices (Delios \& Henisz, 2000; Xu \& Shenkar, 2002; Aybar \& Ficici, 2009; White III et al., 2015). The variable degree of diversification assesses whether the acquisition involved entering a business that was 
not already in the acquirer's portfolio, assessed at the four-digits SIC codes. The variable was measured as a dichotomous variable using the data collected from SDC, where acquisitions outside acquirer previous range of four-digit SIC codes were coded "1" and acquisitions of target with at least one equal SIC code of the acquirer firm were coded " 0 ".

The variable experience in CBAs captures acquirer firms' capability of conducting CBAs. The literature emphasizes the importance of international experience for the multinationals entry mode choice decision-making process (Johanson \& Valhne, 1977; Gaur \& Lu, 2007; Dow \& Larimo, 2009, 2011; Arslan \& Larimo, 2011; Elango et al., 2013; Lebedev et al., 2015). The variable was computed as the sum of the number of cross-border acquisitions by the acquirer between 1985 (the first year SDC started reporting non-US transactions) and the focal deal. Data was collected from SDC and measured as the number of prior cross-border acquisitions completed by the acquirer firms.

Experience in host region identifies whether the acquirer firm already possessed previous acquisition experience in the host country region. Dow and Larimo (2011) outlined that prior location experience thus matter for firms in selecting the entry mode since prior experience reduce the risks and uncertainties for firms. Data was obtained from SDC Platinum and computed as a dichotomous variable taking the value of "1" when the acquirer firm had prior experience in the host region, and " 0 " otherwise.

Experience in host country, following Dow and Larimo (2011), captures the influence of cluster-specific experiences in the MNE strategic decision-making process. In essence, this variable identifies whether the acquirer firms had prior acquisition experience specifically in the host country. Computations were based on data collected from the SDC Platinum, and the variable was coded dichotomously with " 1 " when the acquirer firm had previous experience in the host country, and " 0 " otherwise.

The variable industry relatedness identifies whether the acquisition is made by the acquirer in an industry that was not already in the acquirer's SIC codes list at the three digit classification. This variable allows controlling for information asymmetries between the acquirer and the target firm (Chari \& Chang, 2009). Data on the SIC codes of acquirer and target firms was collected from SDC and the variable was operationalized as a dummy variable that took the value of " 1 " if the acquired firm was in the same industry as the acquirer at the three-digit SIC code classification, and "0" otherwise. 
The variable target is high-tech identifies whether the target firm operates in a high-tech industry. This variable was chosen because previous research suggests that, when institutional uncertainty increases, firms should pursue a full acquisition because it "could potentially allow the firms to better protect their newly acquired technology in an unfamiliar institutional setting" (Elango et al., 2013, p. 12). Data for this variable is explicitly reported in the SDC Platinum database. The industries considered for qualifying the target firm as belonging to a high-tech industry are the following: communications; computer equipment; biotechnology; and electronics. The variable was coded dichotomously with "1" when the acquired firm belongs to the high-tech industry group and coded " 0 " otherwise.

At the country level, I have included four variables. I have controlled for the host country inflation that is a commonly used indicator of macroeconomic stability. This variable is used as the inflation rate in host country in the year prior to the acquisition. The Euromoney's Special Report 2015 outlines the effects of the host country inflation over both interest rates and currency exchange rates, thus crucial for multinationals to be able to trade across borders under more stable conditions. Data was collected from World Bank, World Development Indicators, 2015.

The variable acquirer nation GDPpc accounts for the home country gross domestic product (GDP) per capita, since the country's wealth is likely to influence the choice of entry mode and ownership (Meyer et al., 2009; Dikova \& Brouthers, 2016). Data for the GDP was collected from the World Bank, and specifically the World Development Indicators made available in 2015. Following previous studies, I have used the logarithm of US dollar GDP per capita (Hernández \& Nieto, 2015; Elango et al., 2013).

The variable cultural distance accounts for the cultural differences between home and host countries. The international business literature has been burgeoning in highlighting the influence of cultural differences in managerial decisions, performance and entry modes (Kogut \& Singh, 1988; Hofstede, 1984, 1993; Aybar \& Ficici, 2009; Elango et al., 2013). Data for cultural distance were obtained from Berry et al.'s (2010) database and is based on the Euclidian distance using Hosfetede's (1980) values and Kogut and Singh (1988) formula.

The variable geographic distance represents the distance between home and host countries. The cost of doing business abroad is likely to increase with physical distance, since farther away operations are more difficult to monitor and manage, and this 
variables has been extensively used in prior research (Brouthers \& Brouthers, 2000, 2001; Hernández \& Nieto, 2015; Ang et al., 2015). Data were obtained from Berry et al.'s (2010) database, based on the distance between the countries' capital cities.

The year when the transaction took place was also controlled for to account for the possibility of variations in the ownership stake choices across time. I have included a dummy variable for each year of the sample (Dow \& Larimo, 2011), 2009 to 2015. 
Table 3. Description of the variables

\begin{tabular}{|c|c|c|}
\hline Variable & Description & Source \\
\hline Ownership & $\begin{array}{l}\text { A threshold of } 95 \% \text { of the target equity to qualify } \\
\text { the operation as a full acquisition (Dikova, 2009; } \\
\text { Elango et al., 2013) was coded "1", otherwise it } \\
\text { was coded "0". }\end{array}$ & SDC Platinum \\
\hline $\begin{array}{l}\text { administrative } \\
\text { distance }\end{array}$ & $\begin{array}{l}\text { Differences in colonial ties, language, religion, } \\
\text { and legal systems between home and host } \\
\text { countries. }\end{array}$ & Berry et al. (2010) \\
\hline knowledge distance & $\begin{array}{l}\text { Differences in patents and scientific production } \\
\text { between home and host countries. }\end{array}$ & Berry et al. (2010) \\
\hline $\begin{array}{l}\text { target institutional } \\
\text { development }\end{array}$ & $\begin{array}{l}\text { Proxy for the level of host country institutional } \\
\text { development using United Nations Human } \\
\text { Development Index calculated for each country } \\
\text { yearly. }\end{array}$ & $\begin{array}{l}\text { United Nations, } \\
\text { Human Development } \\
\text { Reports }\end{array}$ \\
\hline transaction value & $\begin{array}{l}\text { Acquisition transaction value (millions US } \\
\text { dollars). }\end{array}$ & SDC Platinum \\
\hline $\begin{array}{l}\text { degree of } \\
\text { diversification }\end{array}$ & $\begin{array}{l}\text { The acquisitions made by the acquirer in a } \\
\text { business that was not already in the acquirer's } \\
\text { SIC codes list at the four digit classification, are } \\
\text { coded "1". Otherwise, acquisitions are coded "0". }\end{array}$ & SDC Platinum \\
\hline experience in $C B A s$ & $\begin{array}{l}\text { Sum of the number of international acquisitions } \\
\text { made by the acquirer in previous years. }\end{array}$ & SDC Platinum \\
\hline $\begin{array}{l}\text { experience in host } \\
\text { region }\end{array}$ & $\begin{array}{l}\text { Dummy variable coded "1" if the acquirer had } \\
\text { experience in acquisitions from previous years in } \\
\text { the host region. }\end{array}$ & SDC Platinum \\
\hline $\begin{array}{l}\text { experience in host } \\
\text { country }\end{array}$ & $\begin{array}{l}\text { Dummy variable coded " } 1 \text { " if the acquirer had } \\
\text { experience in acquisitions from previous years in } \\
\text { the host country. }\end{array}$ & SDC Platinum \\
\hline industry relatedness & $\begin{array}{l}\text { Dummy variable which is coded " } 1 \text { " if the } \\
\text { acquired firm is in the same industry as the } \\
\text { acquirer at the three-digit SIC code } \\
\text { classification, and coded " } 0 \text { " otherwise. }\end{array}$ & SDC Platinum \\
\hline target is high-tech & $\begin{array}{l}\text { Dummy variable coded " } 1 \text { " if the variable is } \\
\text { considered operating in an high tech industry } \\
\text { group according with SDC Platinum database, } \\
\text { and coded " } 0 \text { " if not. }\end{array}$ & SDC Platinum \\
\hline host country inflation & $\begin{array}{l}\text { Inflation rate in the host country in the year } \\
\text { previous to the acquisition deal. }\end{array}$ & $\begin{array}{l}\text { World Bank, } \\
\text { World Development } \\
\text { Indicators } 2015 \\
\end{array}$ \\
\hline $\begin{array}{l}\text { acquirer nation log } \\
\text { GDPpc }\end{array}$ & Log value of the home country GDP per capita. & $\begin{array}{c}\text { World Bank, } \\
\text { World Development } \\
\text { Indicators } 2015 \\
\end{array}$ \\
\hline cultural distance & $\begin{array}{l}\text { Differences in attitudes towards authority, trust, } \\
\text { individuality, and importance of work and } \\
\text { family, between home and host countries. }\end{array}$ & Berry et al. (2010) \\
\hline geographic distance & $\begin{array}{l}\text { Great circle distance between geographic center } \\
\text { of home and host countries. }\end{array}$ & Berry et al. (2010) \\
\hline
\end{tabular}




\subsection{Procedures of analyses}

To test the hypotheses I used binary logistic regression (BLR) since the dependent variable is the ownership coded dichotomously. The use of this method follows previous research (Dow \& Larimo, 2011; Elango et al., 2013) and is appropriate because of the dichotomous nature of the dependent variable. A positive and significant coefficient indicates that a variable is associated to a higher likelihood that a full acquisition is performed. Following prior research, I have used one year lagged values between the dependent variable and the independent variables ensuring the direction of causality (e.g., Chen et al., 2012). The regression model used to test the hypotheses had the following specification:

Ownership $=b_{0}+b_{1}$ administrative distance $+b_{2}$ knowledge distance $+b_{3}$ target institutional development $+b_{4}$ target institutional development $x$ administrative distance $+b_{5-n}($ Controls $)+\varepsilon$.

Moreover, aiming at outlining disparities related to regional idiosyncrasies, the hypotheses were initially analyzed considering the entire sample, and then repeated for two subsamples: one regarding only CBAs made in Africa; and another subsample considering cross-border acquisitions completed outside Africa. Finally, because more than $50 \%$ of total sample relate to South African firms, I further conducted the analysis with additional tests. I thus created two other subsamples of acquirer AfMNEs: one regards South African firms; and another considers non-South African companies. 


\section{Results}

Considering the full sample, Table 4 displays the descriptive statistics and Table 5 displays the correlations between the variables. All the correlations are below 0.70 and the Variance Inflation Factors (VIFs) are lower than 10. Correlations and VIF values were also considered in the subsamples in order to ensure this study is free of multicollinearity and autocorrelation issues. Moreover, Durbin-Watson tests were performed to ensure independency between the errors and reported values close to 2.0, and inside the range $1.5-2.5$.

This study analyses the moderator effect between the level of host country institutional development, target institutional development, and the predictor administrative distance. Following Fairchild and Mackinnon (2009) both variables were centered prior to model estimation to improve interpretation of regression coefficients when testing a moderation model. 
Table 4. Descriptive statistics

\begin{tabular}{|c|c|c|c|c|c|c|c|c|c|c|}
\hline \multirow[b]{2}{*}{ Variables } & \multicolumn{2}{|c|}{ Full Sample } & \multicolumn{2}{|c|}{ CBAs in Africa } & \multicolumn{2}{|c|}{ CBAs Out of Africa } & \multicolumn{2}{|c|}{ South African CBAs } & \multicolumn{2}{|c|}{$\begin{array}{c}\text { non-South African } \\
\text { CBAs }\end{array}$} \\
\hline & Mean & St. Dev. & Mean & St. Dev. & Mean & St. Dev. & Mean & St. Dev. & Mean & St. Dev. \\
\hline ownership & 0.550 & 0.498 & 0.410 & 0.493 & 0.650 & 0.479 & 0.550 & 0.498 & 0.550 & 0.500 \\
\hline administrative distance & 6.880 & 7.225 & 5.405 & 6.154 & 7.725 & 7.394 & 6.307 & 7.949 & 7.692 & 5.992 \\
\hline knowledge distance & 3.928 & 5.094 & 1.043 & 2.505 & 5.871 & 5.412 & 4.547 & 5.266 & 3.059 & 4.723 \\
\hline target institutional development & 0.720 & 0.190 & 0.519 & 0.093 & 0.858 & 0.092 & 0.750 & 0.182 & 0.678 & 0.194 \\
\hline transaction value & 83.328 & 94.501 & 75.341 & 75.139 & 89.170 & 105.861 & 80.165 & 96.722 & 87.096 & 91.896 \\
\hline degree of diversification & 0.510 & 0.501 & 0.390 & 0.490 & 0.580 & 0.495 & 0.570 & 0.497 & 0.420 & 0.496 \\
\hline experience in CBAs & 5.170 & 9.694 & 2.290 & 4.542 & 7.180 & 11.674 & 7.830 & 11.690 & 1.400 & 3.119 \\
\hline experience in host region & 0.340 & 0.474 & 0.320 & 0.469 & 0.360 & 0.481 & 0.410 & 0.493 & 0.240 & 0.428 \\
\hline experience in host country & 0.130 & 0.337 & 0.030 & 0.173 & 0.200 & 0.402 & 0.170 & 0.375 & 0.080 & 0.268 \\
\hline industry relatedness & 0.540 & 0.499 & 0.630 & 0.484 & 0.480 & 0.501 & 0.490 & 0.501 & 0.620 & 0.488 \\
\hline target is high-tech & 0.190 & 0.391 & 0.150 & 0.362 & 0.210 & 0.410 & 0.230 & 0.424 & 0.120 & 0.330 \\
\hline host country inflation & 5.678 & 10.262 & 9.663 & 14.530 & 2.946 & 3.703 & 5.163 & 7.286 & 6.407 & 13.391 \\
\hline acquirer nation log GDP pc & $5,628.087$ & $2,574.579$ & $5,147.353$ & $2,807.288$ & $5,932.181$ & $2,369.907$ & $7,511.288$ & 118.494 & $2,962.632$ & $1,960.833$ \\
\hline cultural distance & 19.852 & 6.444 & 19.445 & 6.517 & 20.092 & 6.381 & 20.859 & 6.036 & 19.414 & 6.944 \\
\hline geographic distance & $6,092,588$ & $4,071.340$ & $2,734.070$ & $1,644.898$ & $8,389.736$ & $3,609.058$ & $7,663.067$ & $3,868.054$ & $3,869.757$ & $3,239.851$ \\
\hline
\end{tabular}

2 and 4 were mean centered). 
Table 5. Correlations matrix

\begin{tabular}{|c|c|c|c|c|c|c|c|c|c|c|c|c|c|c|c|}
\hline Var & ables & 1 & 2 & 3 & 4 & 5 & 6 & 7 & 8 & 9 & 10 & 11 & 12 & 13 & 14 \\
\hline 1 & Ownership & 1.000 & & & & & & & & & & & & & \\
\hline 2 & administrative distance & 0.042 & 1.000 & & & & & & & & & & & & \\
\hline 3 & knowledge distance & $0.172 * * *$ & 0.024 & 1.000 & & & & & & & & & & & \\
\hline 4 & target inst. development & $0.308 * * *$ & 0.052 & $0.571^{* * *}$ & 1.000 & & & & & & & & & & \\
\hline 5 & transaction value & 0.089 & 0.015 & 0.023 & 0.051 & 1.000 & & & & & & & & & \\
\hline 6 & degree of diversification & -0.085 & 0.036 & $0.117^{* *}$ & $0.199 * * *$ & -0.048 & 1.000 & & & & & & & & \\
\hline 7 & experience in CBAs & $0.116 * *$ & -0.070 & 0.072 & $0.221 * * *$ & 0.077 & $0.159^{* * * *}$ & 1.000 & & & & & & & \\
\hline 8 & experience in host region & -0.019 & -0.080 & -0.018 & $-0,011$ & $0.185^{* * *}$ & 0.085 & $0.557 * * *$ & 1.000 & & & & & & \\
\hline 9 & experience in host country & 0.084 & -0.106 & 0.065 & $0,230 * * *$ & 0.083 & $0.118 * *$ & $0.483 * * *$ & $0.543^{* * *}$ & 1.000 & & & & & \\
\hline 10 & industry relatedness & 0.094 & -0.017 & $-0.115^{* *}$ & $-0.168^{* * *}$ & 0.033 & $-0.909 * * *$ & -0.105 & -0.086 & -0.080 & 1.000 & & & & \\
\hline 11 & target is high-tech & 0.106 & -0.026 & 0.096 & 0.102 & $0.143 * *$ & $-0.145^{* *}$ & $0.260 * * *$ & 0.105 & 0.104 & $0.214 * * *$ & 1.000 & & & \\
\hline 12 & host country inflation & -0.076 & -0.010 & $-0.229 * * *$ & $-0.343 * * *$ & 0.050 & -0.090 & -0.087 & -0.001 & -0.084 & 0.079 & -0.064 & 1.000 & & \\
\hline 13 & acquirer nation $\log$ GDP pc & -0.016 & $-0.160 * *$ & $0.120 * *$ & $0.287 * * *$ & 0.025 & $0.193^{* * *}$ & $0.226 * * *$ & $0.141^{* *}$ & 0.131 ** & $-0.170^{* * *}$ & 0.107 & $-0.227 * * *$ & 1.000 & \\
\hline 14 & cultural distance & -0.020 & 0.004 & 0.040 & 0.078 & 0.053 & $0.125 * *$ & 0.011 & -0.004 & 0.065 & $-0.128 * *$ & -0.021 & $-0.151^{* * *}$ & $0.134 * *$ & 1.000 \\
\hline 15 & geographic distance & $0.215^{* * *}$ & 0.097 & $0.469 * * *$ & $0.665^{* * * *}$ & 0.056 & $0.170^{* * *}$ & $0.340 * * *$ & 0.080 & $0.239 * * *$ & $-0.146^{* * *}$ & $0.170^{* * *}$ & $-0.266 * * *$ & $0.254 * * *$ & 0.104 \\
\hline
\end{tabular}


Table 6 presents the statistical results of the tests of the hypothesis. Model 0 includes only the control variables. Models 1 to 4 test the hypotheses. Model 5 is the complete model. The explanatory power of all models are ensured as their Chi-square values are significant at the $\mathrm{p}<0.05$ level.

Hypothesis 1 proposed that greater administrative distance will induce AfMNEs to seek partial ownership stakes. The coefficient for administrative distance in Model 1 is positive and does not have statistical significance. Thus, Hypothesis 1 cannot be confirmed. The positive sign of the coefficient could be related to AfMNEs need to better protect themselves in environments that provide scarce legal protection rights for foreign investors.

Hypothesis 2 suggested that greater knowledge distance between home and host countries will induce AfMNEs to seek partial ownership stakes. The coefficient in Model 2 is positive, which is in opposite direction with our expectation, and does not have statistical significance. Thus, I fail to confirm Hypothesis 2. One possible explanation for the positive sign of this coefficient can be related with the fact that the main sample is biased towards CBAs made out of Africa (184 out of 314) and countries outside the African continent are generally more institutionally developed than AfMNEs home countries. Therefore, AfMNEs might be facing fewer legitimacy problems because of being entering market friendly environments abroad, which induce managers to opt for higher ownership stake choices.

Hypothesis 3 proposed that greater institutional development of the host country will induce AfMNEs to seek full ownership stakes. The coefficient in Model 3 evidences a strongly significant positive effect $(\beta=3.872, \mathrm{p}<0.01)$. Thus, Hypothesis 3 was supported. This result supports the theoretical arguments arguing that advanced institutional settings, with fewer institutional voids, ease the costs of doing business abroad (Chan et al., 2008; Meyer, 2001), pose less legitimacy challenges and induce managers to opt for higher ownership stakes when engaging in a CBA.

Hypothesis 4 proposed that greater institutional development of the host country moderates the relationship between administrative distance and the choice of ownership stake such that the effects of administrative distance on the choice of ownership stake are weaker when the level of the host country institutional development is higher. Model 4 shows a negative coefficient, and hence in the hypothesized direction, but not significant. Hence, I fail to confirm Hypothesis 4. Cross-country administrative distance poses obstacles for managers to realize host country's commercial law adequacy and the 
quality of its enforcement (White III et al., 2015). The absence of statistical significance for the moderation effect of the target institutional development over the effect of administrative distance on AfMNEs' ownership stake choices might be related with a possible separation made by AfMNEs managers when analyzing the challenges presented by cross-country distances and those posed by the existence of institutional voids abroad. 
Table 6. Logistic regression results (African CBAs)

\begin{tabular}{|c|c|c|c|c|c|c|c|c|c|c|c|c|}
\hline & Model 0 & & Model 1 & & Model 2 & & Model 3 & & Model 4 & & Model 5 & \\
\hline administrative distance & & & 0.001 & & & & & & 0.001 & & 0.001 & \\
\hline knowledge distance & & & & & 0.046 & & & & & & -0.002 & \\
\hline target institutional development & & & & & & & 3.872 & $* * *$ & 3.945 & $* * *$ & 3.955 & $* * *$ \\
\hline target inst. development $\mathrm{x}$ adm. distance & & & & & & & & & -0.143 & & -0.143 & \\
\hline transaction value & 0.002 & & 0.002 & & 0.002 & & 0.002 & & 0.002 & & 0.002 & \\
\hline degree of diversification & -0.409 & & -0.412 & & -0.374 & & -0.543 & & -0.476 & & -0.478 & \\
\hline experience in CBAs & 0.028 & & 0.028 & & 0.030 & $*$ & 0.029 & & 0.029 & & 0.029 & \\
\hline experience in host region & -0.656 & $*$ & -0.656 & $*$ & -0.648 & $*$ & -0.396 & & -0.416 & & -0.415 & \\
\hline experience in host country & 0.433 & & 0.437 & & 0.454 & & 0.119 & & 0.073 & & 0.070 & \\
\hline industry relatedness & 0.089 & & 0.087 & & 0.167 & & 0.109 & & 0.112 & & 0.110 & \\
\hline target is high-tech & 0.209 & & 0.210 & & 0.165 & & 0.222 & & 0.272 & & 0.274 & \\
\hline host country inflation & -0.009 & & -0.009 & & -0.007 & & 0.002 & & 0.001 & & 0.001 & \\
\hline cultural distance & -0.005 & & -0.005 & & -0.006 & & -0.002 & & -0.004 & & -0.004 & \\
\hline geographic distance & 0.000 & $* * *$ & 0.000 & $* * *$ & 0.000 & $* *$ & 0.000 & & 0.000 & & 0.000 & \\
\hline year dummies & Yes & & Yes & & Yes & & Yes & & Yes & & Yes & \\
\hline Nagelkerke R Square & 0.139 & & 0.139 & & 0.149 & & 0.203 & & 0.210 & & 0.210 & \\
\hline Chi-square & 34.446 & $* * *$ & 34.452 & $* *$ & 37.007 & $* * *$ & 51.764 & $* * *$ & 53.707 & $* * *$ & 53.710 & $* * *$ \\
\hline$-2 \log$ likelihood & 397.584 & & 397.577 & & 395.022 & & 380.266 & & 378.322 & & 378.320 & \\
\hline $\mathrm{N}$ & 314 & & 314 & & 314 & & 314 & & 314 & & 314 & \\
\hline
\end{tabular}

$* \mathrm{p}<0.10, * * \mathrm{p}<0.05, * * * \mathrm{p}<0.01$.

Dependent variable: Full ownership $=1$ vs Partial ownership $=0$. 
Further analyses were done in order to ensure the validity of previous results and provide further insights by testing the hypotheses in different institutional contexts.

\subsection{Robustness checks}

Robustness tests were conducted to verify whether the results still hold when considering the percentage of ownership acquired as the predicted variable. Therefore, hypotheses 1 to 4 were tested using Ordinary Least Squares (OLS). OLS regression was chosen given the continuous nature of the predicted variable. Thus, the analysis was performed with the percentage of ownership acquired as the dependent variable, instead of using a dichotomous coding.

Results are shown in Table 7 and are consistent with the results obtained using Binary Logistic Regression analysis, suggesting that AfMNEs motives for pursuing higher levels of equity in a CBA are similar to those when the firms opt for a full acquisition. Hence, the institutional contexts that lead AfMNEs to pursue a full acquisition (acquisition of a share equal or greater than $95 \%$ of total target's capital) may be quite the same to those that induce the firms to acquire the majority of the control of the target company as well. The level of institutional development of the host country evidences a positive relationship with AfMNEs' search for higher levels of control. The analysis of distance, regarding administrative and knowledge cross-country differences, could not achieve statistical significance which might be related to both the heterogeneity of firms under analysis regarding resource differences (Oliver, 1997) and the dependence on individual managers' perceptions for choosing the appropriate ownership strategy.

However, OLS results regarding the control variables deserve a careful analysis since they generally confirm prior management theories.

The transaction value coefficient across models in Table 7 is statistical significant and evidences a positive relationship between the likelihood of being targeted higher ownership stakes when the value involved in the transaction increases. This result is in line with the view that higher control modes are appropriated for the management of increasing risks (Xu \& Shenkar, 2002; Chari \& Chang, 2009; Kedia \& Bilgili, 2015).

By the same token, although not statistically significant, the variable target is high-tech consistently reports a positive relationship with the dependent variable. This result is in line with previous research which stands that increasing asset specificity will likely lead to higher ownership stake choices (Ando, 2012). 
The variable degree of diversification evidences a negative relationship with the full acquisition ownership choice. Although the coefficient never achieved statistical significance in any model, this negative relationship between ownership and the predictor degree of diversification is expectable because entering an unfamiliar business involves higher levels of uncertainty (Delios \& Henisz, 2000; Xu \& Shenkar, 2002; Aybar \& Ficici, 2009; White III et al., 2015).

Also, it is important to outline the consistent and opposite relationship reported by the coefficients for the control variables experience in host region and experience in CBAs. This study finds that there is a decreasing probability of an AfMNE pursuing higher ownership stakes in the acquisition when the firm's experience in the host region increases, while the likelihood of pursuing a higher control mode acquisition increases when the firm's general experience with acquisitions increases. Dow and Larimo (2011, p. 321) explain that cluster-specific experiential knowledge (such as experience in host region) and general internationalization knowledge (such as the knowledge acquired by AfMNEs through prior acquisitions) are "both significantly related to establishment mode choices, but in opposite directions".

The authors further explain that the first form of knowledge is often of a tacit nature, which likely impacts MNEs perceptions of distance towards the foreign country, while the second form of knowledge is more related with the firm internal management processes and ability to manage integration costs. Herein, the negative coefficient found for the relationship between percentage of ownership acquired and experience in host region seems to unveil that AfMNEs' managers increasing knowledge about the host region consolidates their perceptions concerning the hampering effects of perceived distance, and increases their ability to promote local partnerships to better overcome those difficulties. Conversely, the positive coefficient found for the relationship between percentage of ownership acquired and the increasing cross-border acquisition experience suggests that the likelihood of an AfMNE pursuing a full ownership acquisition increases with the firm's improvement in its internal management capabilities regarding the post-acquisition integration process. 
Table 7. OLS regression results (African CBAs)

\begin{tabular}{|c|c|c|c|c|c|c|c|c|c|c|c|c|}
\hline & Model 0 & & Model 1 & & Model 2 & & Model 3 & & Model 4 & & Model 5 & \\
\hline administrative distance & & & 0.051 & & & & & & 0.050 & & 0.053 & \\
\hline knowledge distance & & & & & 0.582 & & & & & & 0.108 & \\
\hline target institutional development & & & & & & & 40.043 & $* * *$ & 40.437 & $* * *$ & 39.111 & $* * *$ \\
\hline target inst. development $x$ adm. distance & & & & & & & & & -1.848 & & -1.819 & \\
\hline transaction value & 0.036 & $* *$ & 0.036 & $* *$ & 0.036 & $* *$ & 0.033 & $*$ & 0.034 & $* *$ & 0.034 & $* *$ \\
\hline degree of diversification & -12.480 & & -12.591 & & -12.153 & & -13.404 & $*$ & -12.585 & $*$ & -12.516 & $*$ \\
\hline experience in $C B A s$ & 0.474 & $* *$ & 0.476 & $* *$ & 0.508 & $* *$ & 0.478 & $* *$ & 0.479 & $* *$ & 0.486 & $* *$ \\
\hline experience in host region & -10.361 & $* *$ & -10.378 & $* *$ & -10.198 & $* *$ & -7.412 & $*$ & -7.839 & $*$ & -7.900 & $*$ \\
\hline experience in host country & 3.598 & & 3.739 & & 3.681 & & 0.165 & & -0.290 & & -0.143 & \\
\hline industry relatedness & -6.007 & & -6.076 & & -5.169 & & -5.688 & & -5.788 & & -5.647 & \\
\hline target is high-tech & 2.975 & & 2.980 & & 2.363 & & 3.010 & & 3.672 & & 3.548 & \\
\hline host country inflation & -0.147 & & -0.145 & & -0.114 & & -0.024 & & -0.032 & & -0.029 & \\
\hline acquirer nation log GDP pc & -13.001 & $*$ & -12.701 & $*$ & -12.751 & $*$ & -16.379 & $* *$ & -15.472 & $* *$ & -15.304 & $* *$ \\
\hline cultural distance & 0.003 & & 0.001 & & -0.008 & & 0.033 & & 0.007 & & 0.004 & \\
\hline geographic distance & 0.001 & $* *$ & 0.001 & $*$ & 0.001 & & 0.000 & & 0.000 & & 0.000 & \\
\hline year dummies & Yes & & Yes & & Yes & & Yes & & Yes & & Yes & \\
\hline Adjusted R Square & 0.066 & & 0.063 & & 0.070 & & 0.097 & & 0.098 & & 0.095 & \\
\hline $\mathrm{F}$ & 2.291 & $* * *$ & 2.160 & $* * *$ & 2.315 & $* * *$ & 2.877 & $* * *$ & 2.696 & $* * *$ & 2.563 & $* * *$ \\
\hline $\mathrm{N}$ & 314 & & 314 & & 314 & & 314 & & 314 & & 314 & \\
\hline
\end{tabular}

Dependent variable: Percentage of ownership acquired. $* \mathrm{p}<0.10, * * \mathrm{p}<0.05, * * * \mathrm{p}<0.01$. 


\subsection{Post-hoc analyses}

Post-hoc analyses were conducted to test the hypotheses using subsamples of the dataset for better identifying AfMNEs ownership strategic choices according to the disparate institutional contexts faced by the acquiring firms. In general, as shown by the descriptive statistics shown in Table 4, it is expectable that when AfMNEs engage in CBAs in Africa will face more familiar and underdeveloped institutional settings, and that CBAs made out of Africa will occur in more unfamiliar environments with higher levels of institutional development. Both instances may lead to specific ownership choices. I expect that the analysis of each subsample's results may enhance our understanding over how cross-country differences and institutional voids effects combine to influence AfMNES' ownership stake choices, and how those effects change according to the institutional context at hand.

Table 8 displays the coefficients of the logistic regression analysis for the subsample composed by the acquisitions exclusively performed in Africa. This more specific institutional context presents a general situation where the institutional setting faced by the AfMNE is likely to be both familiar and underdeveloped. In this case, I expect AfMNEs to mostly face legitimacy challenges related to hurdles posed by the existence of institutional voids abroad.

Model 1, which tests Hypothesis 1 for this subsample, shows a positive coefficient for the relationship between administrative distance and ownership. Albeit the signal of the coefficient is in opposite direction of what has been theoretically hypothesized, it confirms the result obtained in Table 6 for the full sample. Nonetheless, this result is in line with La Porta et al. (1998) findings. Spite these authors state that concentration of ownership is negatively related to investor protections, they also outline that the absence of good quality of law enforcement along with insufficient accounting standards induce investors to a response of ownership concentration. In these instances, higher ownership stakes become a surrogate for legal protection, either because of law inadequacy or because of inefficient law enforcement mechanisms. This result might be a consequence of AfMNEs perceptions of weak law enforcement in many African host countries.

Model 2 in Table 8 tests Hypothesis 2 for acquisitions made inside Africa. Conversely to the result obtained for the full sample, the coefficient for the relationship between the dependent variable ownership and the independent variable knowledge distance is negative. Although the coefficient does not have statistical significance, the negative sign in this instance, being in opposition to the result obtained for the full 
sample, suggest that higher legitimacy problems related with knowledge distance may arise when AfMNEs enter other African countries than when engage in a CBA outside the African continent.

Despite the reasonably small sample size $(\mathrm{N}=130)$ Model 3 shows a positive coefficient and statistically significant $(\beta=5.329, \mathrm{p}<0.05)$ for the variable target institutional development, thus confirming Hypothesis 3 in this subsample, and in line with the result obtained for the full sample. It suggests that the higher the level of institutional development in the host country, the lower the legitimacy problems AfMNEs must deal with, and the higher the ownership stake the firms are aiming at.

When looking at Model 4 in Table 8, which tests the moderation effect between administrative distance and the target institutional development, the coefficient turns negative compared with the main sample, suggesting that the absence of institutional voids abroad lead AfMNEs' managers to focus on the management of legitimacy in the host country since the foreign investors legal protection may be a minor concern in this instance. The coefficient does not have statistical significance. Thus, Hypothesis 4 is not supported within this subsample.

Model 5 in Table 8 reaches a Nagelkerke $\mathrm{R}^{2}$ above 0.20 (Arslan \& Larimo, 2011) and shows all the coefficients according to hypotheses 1 to 3 , although none of them was able to achieve statistical significance. When considering in tandem, cross-country distances - regarding administrative distance and knowledge distance - and the level of institutional development of the host country, in what concerns to acquisitions made inside Africa, AfMNEs seem to resort to ownership strategies better aligned for the management of legitimacy abroad. 
Table 8. Logistic regression results (AfMNEs CBAs in Africa)

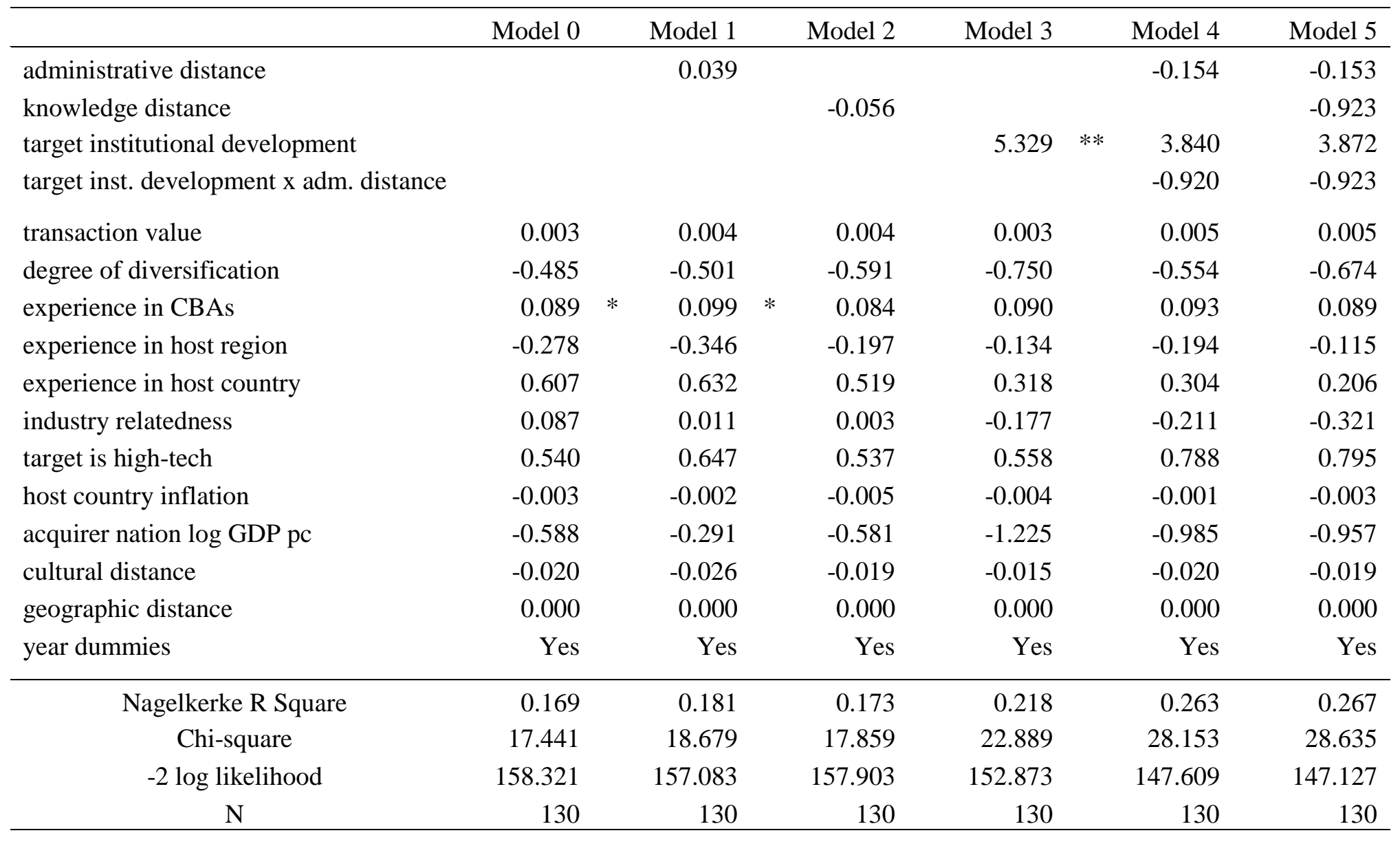

Dependent variable: Full ownership $=1$ vs Partial ownership $=0 . * \mathrm{p}<0.10, * * \mathrm{p}<0.05, * * * \mathrm{p}<0.01$. 
Table 9 displays the coefficients for the subsample composed by the acquisitions exclusively made out of Africa. I expect that CBAs made out of Africa will present AfMNEs with more unfamiliar and developed institutional environments. In this instance, since the host countries are generally economically more developed than the AfMNE's home country, I expect that the acquirer main concerns for gaining legitimacy abroad mostly relate to cross-country differences regarding administrative and knowledge dimensions.

Model 1 in Table 9 tests Hypothesis 1. Also in this subsample the coefficient for the relationship between the independent variable administrative distance and the dependent variable ownership is positive and does not have statistical significance. Once again Hypothesis 1 failed to be supported. However, in this particular case, the value of the coefficient diminishes its magnitude compared to the main sample, or compared with the sample for acquisitions made in Africa as well. Thus, in acquisitions made out of Africa the administrative distance perceived by the managers seems to loose relevance for their ownership decisions.

Model 2 in Table 9 shows a positive coefficient for the variable knowledge distance. Albeit the knowledge distance coefficient does not have statistical significance this result is aligned with Elango and Pattnaik (2011) view. These authors state that MNEs from emerging economies use CBAs in developed economies to acquire strategic resources and overcoming entry barriers in the host market, while reducing "restraints created by institutional and market conditions by their home markets" (Elango \& Pattnaik, 2011, p. 463). Partnerships are often used by firms seeking intangible resources and/or aiming at capturing opportunities (Meyer et al., 2009; Li et al., 2014). Therefore, since the CBAs in the database are biased towards acquisitions in more developed countries (202 out of 314 , see Table 2), it is plausible that the positive relationship between ownership and knowledge distance may be related with AfMNEs being targeting at the host countries' tangible resources and codified knowledge, while seeking to exploit opportunities at home. AfMNEs will likely have developed their absorptive capacities in order to transfer the acquired knowledge and know-how to their home countries and translate it into a strategic competitive advantage (Chen et al., 2012; Osabutey et al, 2014). The heterogeneity of capabilities (Sun, Peng, Ren and Yan, 2012) between AfMNEs might explain the coefficient's absence of statistical significance.

Model 3 in Table 9 shows a positive coefficient and statistically significant $(\beta=5.604, p<0.05)$ for the variable target institutional development, thus confirming 
Hypothesis 3 in this subsample, and also in line with the result obtained for the full sample. It suggests that the higher the level of institutional development in the host country outside Africa, the lower the legitimacy hurdles presented abroad, and the higher the levels of equity control sought by AfMNEs.

Model 4 in Table 9, which tests the moderation effect of the level of institutional development of the host country and cross-country administrative distance, exhibits a positive coefficient for the relationship between the moderator effect and the dependent variable ownership, suggesting that the absence of institutional voids abroad lead AfMNEs' managers to focus on the exploitation of their endeavor without higher concerns regarding the management of legitimacy, even when sensing administrative differences between home and host countries.

Model 5 in Table 9 also reaches a Nagelkerke $\mathrm{R}^{2}$ above 0.20 (Arslan \& Larimo, 2011) and shows a significant coefficient for the independent variable target institutional development $(\beta=6.621, \mathrm{p}<0.05)$. Therefore, also in the subsample for CBAs made by AfMNEs out of Africa, when the host country presents more market friendly environments with fewer institutional voids, AfMNEs seem to resort to higher levels of ownership stakes and face less legitimacy concerns abroad. 
Table 9. Logistic regression results (AfMNEs CBAs out of Africa)

\begin{tabular}{|c|c|c|c|c|c|c|c|c|c|c|c|c|}
\hline & Model 0 & & Model 1 & & Model 2 & & Model 3 & & Model 4 & & Model 5 & \\
\hline administrative distance & & & 0.008 & & & & & & 0.005 & & 0.004 & \\
\hline knowledge distance & & & & & 0.019 & & & & & & -0.025 & \\
\hline target institutional development & & & & & & & 5.604 & $* *$ & 5.858 & $* *$ & 6.621 & $* *$ \\
\hline target inst. development $\mathrm{x}$ adm. distance & & & & & & & & & 0.130 & & 0.119 & \\
\hline transaction value & 0.002 & & 0.002 & & 0.002 & & 0.002 & & 0.002 & & 0.002 & \\
\hline degree of diversification & -0.488 & & -0.507 & & -0.484 & & -0.415 & & -0.491 & & -0.474 & \\
\hline experience in CBAs & 0.038 & $*$ & 0.038 & $*$ & 0.039 & $*$ & 0.038 & $*$ & 0.039 & $*$ & 0.037 & $*$ \\
\hline experience in host region & -1.339 & $* *$ & -1.332 & $* *$ & -1.316 & $* *$ & -1.105 & $* *$ & -1.089 & $*$ & -1.095 & $*$ \\
\hline experience in host country & 0.704 & & 0.723 & & 0.708 & & 0.626 & & 0.677 & & 0.659 & \\
\hline industry relatedness & 0.227 & & 0.223 & & 0.255 & & 0.360 & & 0.330 & & 0.311 & \\
\hline target is high-tech & 0.092 & & 0.083 & & 0.048 & & -0.090 & & -0.129 & & -0.088 & \\
\hline host country inflation & -0.122 & $* *$ & -0.124 & $* *$ & -0.112 & $* *$ & -0.056 & & -0.054 & & -0.058 & \\
\hline acquirer nation $\log$ GDP pc & -0.513 & & -0.487 & & -0.521 & & -0.763 & & -0.634 & & -0.697 & \\
\hline cultural distance & 0.012 & & 0.012 & & 0.012 & & 0.010 & & 0.011 & & 0.009 & \\
\hline geographic distance & 0.000 & & 0.000 & & 0.000 & & 0.000 & & 0.000 & & 0.000 & \\
\hline year dummies & Yes & & Yes & & Yes & & Yes & & Yes & & Yes & \\
\hline Nagelkerke R Square & 0.199 & & 0.200 & & 0.201 & & 0.235 & & 0.239 & & 0.241 & \\
\hline Chi-square & 28.790 & $* *$ & 28.908 & $* *$ & 29.051 & $* *$ & 34.470 & $* *$ & 35.183 & $* *$ & 35.526 & $* *$ \\
\hline$-2 \log$ likelihood & 210.205 & & 210.087 & & 209.944 & & 204.525 & & 203.811 & & 203.468 & \\
\hline $\mathrm{N}$ & 184 & & 184 & & 184 & & 184 & & 184 & & 184 & \\
\hline
\end{tabular}

$* \mathrm{p}<0.10, * * \mathrm{p}<0.05, * * * \mathrm{p}<0.01$ 
Because CBAs made by South African MNEs accounts for more than 50\% of total sample (184 acquisitions out of 314), I also split the main sample into two more subsamples: one considering the CBAs performed by South Africa's firms; and another encompassing CBAs performed by AfMNEs from home countries other than South Africa. There are two reasons to engage in the analysis of these two subsamples. First, South African MNEs enjoy the possibility of supporting their international expansion endeavors through a governmental agency that provides financial and technical assistance. Thus, the experience and international network relationships already established by this governmental agency may ease South African MNEs challenges for gaining legitimacy abroad, by acting in reducing uncertainties and sharing risks. Because non-South African AfMNEs do not seem to dispose of this type of governmental assistance at home these companies probably face higher difficulties for gaining legitimacy abroad. Second, the results of the main sample obtained in Table 7 may be biased because of other South Africa's specificities, such as higher levels of education or economic development compared with the majority of non-South African AfMNEs home countries. Therefore, it is important to analyze to what extent these home countries' specificities influence the acquirer's ownership strategies for achieving legitimacy abroad.

Table 10 exhibits the results of logistic regression for the CBAs made by MNEs coming from South Africa. Although it was not possible to assess how often and to what extension South African MNEs require their governmental agency assistance when engaging in a CBA, I expect that South African MNEs will experience less difficulties for gaining legitimacy abroad compared with non-South African AfMNEs.

Model 1 in Table 10, which tests Hypothesis 1 within this subsample, shows a positive coefficient for the relationship between administrative distance and ownership, in line with the result obtained in Table 6 for the full sample. It suggests that managers from South African firms opt more often for a full acquisition when cross-country administrative distance increases. Because this result has no statistical significance, caution needs are in place regarding the above interpretation.

Model 2 in Table 10 tests Hypothesis 2 for acquisitions made by South African firms. The coefficient for the relationship between the dependent variable ownership and the independent variable knowledge distance is positive, and in line the result obtained for the main sample. Although the coefficient does not have statistical significance, the positive sign suggests that South African firms prefer full acquisitions 
when engaging in a CBA into knowledge distant countries, which can be explained if South African firms are entering the foreign market aiming at codified knowledge (Kogut \& Singh, 1988) and realizing fewer pressures regarding the achievement of legitimacy abroad (Lu et al., 2008).

Model 3 in Table 10 analyzes Hypothesis 3. As in the previous regression analysis the model shows a positive coefficient and statistically significant $(\beta=3.872, p<0.01)$ for the variable target institutional development, thus confirming Hypothesis 3 in this subsample, and in line with the result obtained for the full sample. It confirms that the higher the level of institutional development in the host country, the lower the legitimacy problems South African MNEs face in the foreign country, and the higher the likelihood of pursuing a full ownership acquisition.

Model 4 in Table 10 tests Hypothesis 4. The coefficient for the moderation effect between administrative distance and the target institutional development is negative and non-significant, similarly to what happened when considering the full sample. Thus, Hypothesis 4 cannot be supported within this subsample.

Model 5 in Table 10 reaches a Nagelkerke $\mathrm{R}^{2}$ above 0.20 (Arslan \& Larimo, 2011) and only confirms statistically the Hypothesis 3, similarly to the results obtained for the main sample. This result suggests that the absence of institutional voids abroad pose fewer legitimacy problems for South African firms when incurring in their international expansion efforts, and that cross-country distances regarding administrative and knowledge dimensions might pose disparate legitimacy problems according to each firm idiosyncrasies. 
Table 10. Logistic regression results (South African CBAs)

\begin{tabular}{|c|c|c|c|c|c|c|c|c|c|c|c|c|}
\hline & Model 0 & & Model 1 & & Model 2 & & Model 3 & & Model 4 & & Model 5 & \\
\hline administrative distance & & & 0.001 & & & & & & 0.001 & & 0.001 & \\
\hline knowledge distance & & & & & 0.046 & & & & & & -0.002 & \\
\hline target institutional development & & & & & & & 3.872 & $* * *$ & 3.945 & $* * *$ & 3.963 & $* * *$ \\
\hline target inst. development $\mathrm{x}$ adm. distance & & & & & & & & & -0.143 & & -0.143 & \\
\hline transaction value & 0.002 & & 0.002 & & 0.002 & & 0.002 & & 0.002 & & 0.002 & \\
\hline degree of diversification & -0.409 & & -0.412 & & -0.374 & & -0.543 & & -0.476 & & -0.478 & \\
\hline experience in CBAs & 0.028 & & 0.028 & & 0.030 & $*$ & 0.029 & & 0.029 & & 0.029 & \\
\hline experience in host region & -0.656 & $*$ & -0.656 & $*$ & -0.648 & $*$ & -0.396 & & -0.416 & & -0.415 & \\
\hline experience in host country & 0.433 & & 0.437 & & 0.454 & & 0.119 & & 0.073 & & 0.070 & \\
\hline industry relatedness & 0.089 & & 0.087 & & 0.167 & & 0.109 & & 0.112 & & 0.110 & \\
\hline target is high-tech & 0.209 & & 0.210 & & 0.165 & & 0.222 & & 0.272 & & 0.274 & \\
\hline host country inflation & -0.009 & & -0.009 & & -0.007 & & 0.002 & & 0.001 & & 0.001 & \\
\hline acquirer nation $\log$ GDP pc & -0.570 & & -0.562 & & -0.539 & & -0.934 & & -0.852 & & -0.854 & \\
\hline cultural distance & -0.005 & & -0.005 & & -0.006 & & -0.002 & & -0.004 & & -0.004 & \\
\hline geographic distance & 0.000 & $* * *$ & 0.000 & $* * *$ & 0.000 & $* *$ & 0.000 & & 0.000 & & 0.000 & \\
\hline year dummies & Yes & & Yes & & Yes & & Yes & & Yes & & Yes & \\
\hline Nagelkerke R Square & 0.139 & & 0.139 & & 0.149 & & 0.203 & & 0.210 & & 0.210 & \\
\hline Chi-square & 34.446 & $* * *$ & 34.452 & $* *$ & 37.007 & $* * *$ & 51.764 & $* * *$ & 53.707 & $* * *$ & 53.710 & $* * *$ \\
\hline-2 log likelihood & 397.584 & & 397.577 & & 395.022 & & 380.266 & & 378.222 & & 378.320 & \\
\hline $\mathrm{N}$ & 184 & & 184 & & 184 & & 184 & & 184 & & 184 & \\
\hline
\end{tabular}

Dependent variable: Full ownership $=1$ vs Partial ownership $=0 . * \mathrm{p}<0.10, * * \mathrm{p}<0.05, * * * \mathrm{p}<0.01$. 
Table 11 exhibits the results of logistic regression for the CBAs made by AfMNEs from home countries other than South Africa. This subsample is mainly composed by AfMNEs coming from economically underdeveloped countries. It is likely that the companies of this subsample are facing the highest challenges regarding the achievement of legitimacy abroad and, therefore, it is important to analyze their ownership choices separately.

Table 11 presents the first instance where the results show statistical significance for the coefficients of administrative distance, in Model 1, and knowledge distance, in Model 5.

In Model 1, Table 11, the coefficient for administrative distance is positive and significant $(\beta=0.093, \mathrm{p}<0.05)$. AfMNEs coming from non-South Africa engage in CBAs mainly in African host countries (65 cases out of 130) while South Africa firms mainly target at host countries located outside Africa (119 cases out of 184). According to La Porta et al. (1998) weak quality of law enforcement along with meager accounting standards induce investors to a response of ownership concentration. Hence, this result might be a consequence not only of the effects of the perceived administrative distance by AfMNEs' managers, but also the effect of accrued institutional voids found in the host country. Although not statistically significant, the negative value found in Model 5 for the coefficient of the moderation between administrative distance and target institutional development, coupled with the decrease in the magnitude of the coefficient for the predictor administrative distance, seems to reinforce this theoretical interpretation of the result obtained in Model 1 for the administrative distance coefficient.

In Model 2, the coefficient for knowledge distance is negative, and in line with the hypothesized direction of the relationship between this predictor and the dependent variable ownership. Although not statistically significant, this result may indicate that cross-country knowledge distance poses some legitimacy hurdles for AfMNEs other than South African firms, inducing the acquirer firms to seek for partnerships in the host country.

In Model 3, Table 11, once again the model shows a positive coefficient and statistically significant $(\beta=4.730, \mathrm{p}<0.01)$ for the variable target institutional development, thus confirming Hypothesis 3 in this subsample, and in line with the result obtained for the full sample. Therefore, I found a positive and statistically significant relationship between the absence of institutional voids abroad and the preference for 
pursuing a full ownership by AfMNEs, confirming that more market friendly environments present fewer difficulties regarding the achievement of legitimacy in the host countries.

Model 4, which tests Hypothesis 4, the moderator effect of target institutional development over administrative distance on the firms' ownership stake choices, shows a positive and statistical significant sign for both predictor variables while failing to statistically confirm the negative sign of the moderation relationship. This result indicates that the effect of moderation may exist. Cumulatively, the coefficient for the moderation effect has opposite sign to those of the predictor variables, both predictors are statistically significant and the Nagelkerke R Square increases, outlining that this Model 4 is more powerful than previous ones for explaining the variance of the dependent variable ownership. Overall, this result suggests that AfMNEs other than South African firms seek higher ownership stakes when cross-country administrative distance increases and when the host country presents fewer institutional voids. Theoretically, the preference for higher ownership stakes when administrative distance increases might be explained by the effort of foreign investors to better protect themselves in unfamiliar regulatory settings (La Porta et al., 1998), while the preference for full ownership stakes in higher developed environments might be explained by fewer legitimacy hurdles for achieving legitimacy abroad in this instance. The negative sign for the moderation effect may indicate that cross-country administrative distance effect is attenuated by the host country institutional development, not only because of the opposition of the sign of the coefficient but also because the magnitude of the coefficient for the predictor administrative distance diminishes from Model 1 to Model 4.

Model 5 in Table 11 is the first instance of the post-hoc analyses where the coefficients for the cross-country knowledge distance and target institutional development are both statistically significant. The coefficient for the relationship between knowledge distance and ownership is negative and statistically significant $(\beta=-0.121, p<0.05)$ which gives support for Hypotheses 2 within this subsample. This result acquires more importance since the sample is relatively small, which adds more meaning to the role of cross-country knowledge differences for the management of legitimacy abroad by AfMNEs - other than those coming from South Africa. This result obtained for the full model gathers accrued importance because it reaches a Nagelkerke $\mathrm{R}$ Square of 0.404 , meaning that this model explains the variation of the dependent 
variable ownership nearly two times better than in previous samples. In practical terms, this result outlines that when target institutional development decreases and crosscountry knowledge distance increases non-South African AfMNEs show preference for entering foreign markets through partnerships in order to better manage legitimacy abroad.

Besides, these results suggest that the effects of the realized institutional distance sensed by managers from non-South African AfMNEs is different from those that are perceived by the managers of South African acquirer firms. Indeed, South African MNEs enjoy the possibility of gathering support from a governmental agency, "The Industrial Development Corporation", which, in their own web page words, "plays a catalytic role in promoting partnerships across industries and across borders", and participate in jointly investment projects throughout Africa (Chen et al., 2016). Thus, the international experience and networks of this organization may contribute to a decrease in the perceived institutional distances of South African MNEs' managers.

Finally, it is worth noting a statistical significant result for the control variable target is high-tech. Considering the subsample presented in Table 11, the coefficient for the relationship between the predictor target is high-tech and the dependent variable ownership is positive and statistically significant in all cases, from Model 0 to Model 5. Elango et al. (2013, p. 4) state that CBA "that involve entry into high-technology industries are more likely to be partial acquisition relative to full acquisitions" mainly because of the existence of information asymmetry between the transaction parties. Nonetheless, these authors highlight that this relationship should be in the opposite direction when MNEs are entering unfamiliar institutional environments. Therefore, one possible explanation for this result may be that non-South African AfMNEs mainly needed to "protect their newly acquired technology in an unfamiliar institutional setting" (Elango et al., 2013, p. 13). 
Table 11. Logistic regression results (non-South African CBAs)

\begin{tabular}{|c|c|c|c|c|c|c|c|c|c|c|c|c|}
\hline & Model 0 & & Model 1 & & Model 2 & & Model 3 & & Model 4 & & Model 5 & \\
\hline administrative distance & & & 0.093 & $* *$ & & & & & 0.087 & $*$ & 0.073 & \\
\hline knowledge distance & & & & & -0.035 & & & & & & -0.121 & $*$ \\
\hline target institutional development & & & & & & & 4.730 & $* * *$ & 4.941 & $* * *$ & 6.365 & $* * *$ \\
\hline target inst. development $\mathrm{x}$ adm. distance & & & & & & & & & -0.045 & & -0.130 & \\
\hline transaction value & 0.001 & & 0.001 & & 0.000 & & 0.001 & & 0.001 & & 0.001 & \\
\hline degree of diversification & -0.578 & & -1.114 & & -0.675 & & -0.993 & & -1.506 & & -1.820 & \\
\hline experience in CBAs & 0.044 & & 0.023 & & 0.053 & & 0.008 & & -0.014 & & 0.004 & \\
\hline experience in host region & -1.774 & $* *$ & -1.865 & $* * *$ & -1.797 & $* * *$ & -1.550 & $* *$ & -1.630 & $* *$ & -1.740 & $* *$ \\
\hline experience in host country & 1.345 & & 1.503 & & 1.194 & & 1.241 & & 1.402 & & 0.963 & \\
\hline industry relatedness & 0.156 & & -0.438 & & 0.034 & & 0.053 & & -0.550 & & -0.899 & \\
\hline target is high-tech & 1.892 & $* *$ & 2.197 & $* *$ & 1.973 & $* *$ & 2.390 & $* * *$ & 2.831 & $* * *$ & 3.263 & $* * *$ \\
\hline host country inflation & 0.035 & & 0.038 & & 0.034 & & 0.049 & & 0.060 & & 0.055 & \\
\hline acquirer nation log GDP pc & 0.867 & & 1.330 & & 0.894 & & -0.098 & & 0.271 & & -0.005 & \\
\hline cultural distance & -0.029 & & -0.038 & & -0.030 & & -0.021 & & -0.033 & & -0.037 & \\
\hline geographic distance & 0.000 & $* * *$ & 0.000 & $* * *$ & 0.000 & $* * *$ & 0.000 & & 0.000 & & 0.000 & \\
\hline year dummies & Yes & & Yes & & Yes & & Yes & & Yes & & Yes & \\
\hline Nagelkerke R Square & 0.257 & & 0.300 & & 0.261 & & 0.340 & & 0.377 & & 0.404 & \\
\hline Chi-square & 27.764 & $* *$ & 33.000 & $* *$ & 28.219 & $* *$ & 38.183 & $* * *$ & 43.085 & $* * *$ & 46.767 & $* * *$ \\
\hline$-2 \log$ likelihood & 151.345 & & 146.109 & & 150.890 & & 140.926 & & 136.024 & & 132.342 & \\
\hline $\mathrm{N}$ & 130 & & 130 & & 130 & & 130 & & 130 & & 130 & \\
\hline
\end{tabular}

Dependent variable: Full ownership $=1$ vs Partial ownership $=0 . * \mathrm{p}<0.10, * * \mathrm{p}<0.05, * * * \mathrm{p}<0.01$. 


\section{Discussion}

In this study I address the effects of disparate institutional contexts faced by MNEs in deciding the ownership choices in CBAs. Although prior literature has addressed the theme of ownership strategic choices in CBAs through the lens of institutional theory (e.g., Elango et al., 2013; Madhok, 1997; Chari and Chang, 2009; Bruton, Peng, Ahlstrom, Stan \& Xu, 2015; Ando, 2012; Kedia \& Bilgili, 2015; Sun et al., 2012; Gaur \& Lu, 2007; De Beule et al., 2014; La Porta et al., 1998) I am not aware of the existence of several studies integrating cross-national differences and legitimacy concerns to identify the MNE's relevant institutional context and its impact on MNEs' ownership strategies.

For AfMNEs entering underdeveloped countries without a strong legitimating position, as it may be enjoyed by MNEs from advanced economies (Kostova et al., 2008), overcoming legitimacy concerns will likely require a quite specific approach. Institutional voids, such as unclear regulatory frameworks, inexperienced bureaucracies, underdeveloped court systems, and institutional settings with corruption issues and weak property rights protection - increase transaction costs (Meyer, 2001; Chan et al., 2008; Abotsi \& Iyavarakul, 2015) and demand different capabilities to survive rather than those required by a developed institutional environment. These environments usually offer opportunities to take advantage of market imperfections but those potential gains can be offset by excessive costs of uncertainty and government arbitrariness (Aybar \& Ficici, 2009). Furthermore, underdeveloped environments inhibit MNEs to properly adapt as the distance grows because there is a growing difficulty in understanding how to achieve legitimacy in the host country (Hernández \& Nieto, 2015) and how to safeguard against private and public expropriation hazards in these settings (Delios \& Henisz, 2000). Mainly, these host institutional settings require network-based capabilities (Ando 2012, Peng, 2003, Peng et al., 2009), where, to be successful, "who

you know" becomes more important than "what you know" (White III et al., 2015). In this instance, this accrued need for legitimacy might induce AfMNEs to seek for partnerships abroad, and/or to rely more heavily in political ties, in order to enable the success of their investment in the foreign market. 
Conversely, when entering host countries that are institutionally developed MNEs face strong pressures from the three institutional pillars (regulative, normative and cognitive) to engage in market-based impersonal exchange (Peng, 2003). Although AfMNEs may lack the capabilities to immediately compete on those markets, the acquired target is already legitimate and fully operating. However, AfMNE's lack of capabilities to deal with a market based economy will likely pose critical legitimacy concerns. Their accrued legitimacy barriers might come from their inferiority regarding technology and know-how. This handicap poses both internal and external legitimacy problems. Internally, the success of the endeavor might be compromised due to integration difficulties between the AfMNE and its subsidiary. Nonetheless, AfMNEs may be able to manage this difficulty because of their specific institutional context. Kostova and Zaheer (1999, p. 75) pose that "the less legitimate local firms are in a particular institutional environment, the less challenge MNEs subunits will face in establishing legitimacy in that host environment". Moreover, Kostova et al. (2008, p. 999) highlight that when something "distinctive [and] appreciated by local constituents" is brought from abroad it is likely that local practices loose predominance. Hence, in this instance, home local pressures for isomorphism are weakening, or even excluded. Regarding concerns over the transfer of new processes and know-how from the subsidiary to the parent firm, it is likely that its acceptance at home will be good since it will enhance AfMNEs competitive advantage. Therefore, the integration between the African parent firm and its subsidiary will likely occur almost free of pressures for the perpetuation of the old fashion practices, remaining the difficulties for being accepted by the host country constituencies.

Specifically, I have examined two dimensions regarding the deterrent effect of cross-national distance on the achievement of legitimacy by MNEs engaging in a CBA: administrative distance and knowledge distance. Both dimensions were considered under Berry et al.'s (2010) framework and gauged their combined effects with the level of institutional development of the host country. These dimensions follow the guidance provided by the literature which outlines: (1) the important role over a country's economic development of both institutional development and factor market development (Hoskisson et al., 2013); and (2) the influence of the regulatory and technological differences on MNEs ability to achieve legitimacy abroad when entering a more advanced host country - in economic terms (Meyer et al., 2014). These two institutional dimensions for assessing cross-national distances seem to be particularly 
relevant within the institutional context of the African continent because they pose several legitimacy challenges that influence AfMNEs ownership stake choices in their international expansion endeavors.

The multitude of institutional idiosyncrasies among African countries enables a deeper understanding over how ownership stake choices change when different legitimacy needs emerge. Particularly, by using a multi-country analysis based in the African context I was able to achieve a wide diversity of institutional contexts. Africa presents a very special context since the legitimacy challenges faced by AfMNEs are magnified by their home countries institutional weaknesses. Furthermore, host countries might look at an AfMNE based on pejorative stereotypes, which hinder the African firm from achieving legitimacy abroad. Even inside the African continent, due to Africa's internal diversity regarding both the regulatory framework across countries and the variety of colonial ties that are still in place, an AfMNE might face higher difficulties for gaining legitimacy in a host country inside their own continent than those required to a foreign firm coming from an economically advanced location. Technological weaknesses pose another potential hurdle for achieving legitimacy when entering host countries located in advanced economies (Meyer et al., 2014). Thus, by resting the analysis in a wide diversity of home and host countries that present disparate institutional environments among themselves, this study outlines how managers adapt their ownership stake choices for enabling the AfMNEs acquiring legitimacy abroad.

Overall, this study gives a number of contributions to the international business theory. In theoretical terms, I adopt an approach of integrating the elements of crossnational distance and direction to assess the extension of legitimacy challenges that MNEs face abroad. When MNEs are setting up their ownership strategies abroad the development of institutions in the host country interacts with managers' perceptions of institutional distance across countries. This interaction influences the ownership strategies that each MNE choses for gaining legitimacy abroad.

In empirical terms, this study outlines how institutional contexts are firm specific and pose different challenges according to the host country under examination. An element of novelty is added by combining the empirical dimensions of administrative and knowledge distances with the level of institutional development of the host country. Furthermore, it consolidates the validity of previous theories in the African context while highlighting the importance of legitimacy when examining a CBA endeavor. 
The results indicate that firms adapt their ownership decisions according to the institutional context at hand but this response encompasses the evaluation of the external environment conditions in relation to each firm specific needs and capabilities. This observation confirms previous research. The literature emphasizes the role of firms unique identity where it is stated that cross-country distance perceptions impact differently their strategic choices according to their own firm specific advantages (FSA) (Rugman et al., 2011), experience (Lebedev et al., 2015; Swoboda et al., 2015; Elango et al., 2013; Arslan \& Larimo, 2011; Dow \& Larimo, 2011, 2009; Gaur \& Lu, 2007; Johanson \& Vahlne, 2009, 1977), and capabilities (Ferreira et al., 2011; Teece et al., 1997). When drawing strategic decisions regarding MNEs international expansion, the need to consider institutional contexts, comprehending home and host countries idiosyncrasies (Hoskisson et al., 2013), is further extended by the literature in the realms of uncertainty management (Hernández \& Nieto, 2015; Chan et al., 2008; Murtha \& Lenway, 1994), opportunity capture (Li et al., 2014; Chen et al., 2012) and FSA exploitation (Rugman et al., 2011; Chan et al., 2008). Thus, the presence or absence of institutional voids in combination with other international business deterrents at the institutional domain - such as those at the regulative, normative and cognitive levels - constitutes the relevant institutional context when a MNE is embracing its strategic decision-making process.

Results suggest that the absence of institutional voids, which is provided by higher levels of institutional development in the host country, is positively related with higher ownership stakes. Moreover, results show that this preference seems to be somewhat independent of firm idiosyncrasies and, therefore, should be a generalizable conclusion to MNEs other than African ones.

Results also suggest that cross-national distance concerns are somehow related to firm specific aspects, outlined in this study by the support of Hypotheses 2 only for CBAs made by African home countries other than South Africa. This result also suggests that cross-national distance deterrents acquire higher preponderance when the presence of institutional voids increases in the host country.

Results did not provide support for the hypothesized relationship of the existence of a moderator effect of the level of host country institutional development over institutional distance considerations in AfMNEs' ownership decisions. This result seems to magnify the separate natures between the concepts of cross-national distance and legitimacy. In fact previous research has already shown that cross-national distance 
is MNE centered and its effects vary according to each firm's idiosyncrasies, such as international experience or other FSA (Johanson \& Vahlne, 1977; Dow \& Larimo, 2009, 2011; Rugman et al., 2011). The achievement of legitimacy, in turn, is dependent on host country's evaluation made by the relevant legitimating actors (Suchman, 1995; Kostova \& Zaheer, 1999; Kostova et al., 2008). Although higher cross-national distance hinders MNEs' legitimacy achievement in the host country (Kostova \& Zaheer, 1999) it is not clear to what extent and under what circumstances this difficulty poses a strategic restriction to MNEs' operations. In this regard, Kostova et al. (2008) and Suchman (1995) pose that MNEs have an option to undertake legitimating strategic actions in the host country. Moreover, internal legitimacy concerns (being consistent within the MNE's system, harmonizing external and internal isomorphic pressures in home and host countries) are dependent on the MNE's international expansion strategy because pursuing a multidomestic strategy - where the company mainly competes locally in many world locations - is different from pursuing a global strategy - where the company competes internationally through the integration of business processes originated in separated countries (Xu \& Shenkar, 2002; Harzing, 2002). Hernández and Nieto (2015) stand that a higher level of regulative development prompts firms to easily obtain legitimacy abroad and that then firms will resort to institutional distance considerations, using the efficiency criteria under the transaction costs approach. Therefore, although increasing cross-country differences instances will likely lead to higher difficulties obtaining legitimacy, increasing the easiness of obtaining legitimacy does not seem to have a direct and proportional impact on diminishing MNEs' perceptions over cross-country distance. Nonetheless the results evidence that there are institutionally distant countries that lead MNEs to higher ownership stake choices.

Notably, despite the huge institutional distance between AfMNEs home countries and their legitimating host countries located in developed economies, AfMNEs opt preferably for a full acquisition when engaging in a CBA into these locations. Albeit these instances present AfMNEs with majored legitimacy challenges due to their extensive problems regarding economic, political and corruption issues at home, results evidence that the absence of institutional voids abroad induces the acquirer firms to opt for higher levels of equity control. This response likely buttresses AfMNEs for gaining legitimacy abroad since the establishment of partnerships abroad might be jeopardized by prejudice and distrust among the host countries' agents towards the acquirer firms. 


\subsection{Limitations and future research avenues}

This study has a number of limitations worth noting. First, AfMNEs international orientation was not controlled for. Although I am aware of the importance of ethnocentric, polycentric or geocentric strategies for MNEs to achieve legitimacy (Harzing, 2002), it was not possible to control for this effect given the use of secondary data. Future research may overcome this limitation by grouping the acquirer firms under examination according to their international orientation because both internal and external legitimacy are affected by this strategic international orientation of the firm. Such research is important because it will extend our understanding over the interaction between organizations and institutions while increasing the accuracy of the theory to explain managerial practice regarding ownership stake choices.

Second, different motives to engage in a CBA can lead to different acquirer strategic ownership behaviors since, for instance, accessing new markets and distribution channels may require different strategies than entering a foreign country for accessing new technologies and know-how, whilst posing different legitimacy challenges in the host country (Meyer et al., 2014). This work did not control for MNEs' motives to embrace a CBA. The interplay between firms' motives and capabilities provides a set of restrictions for engaging in CBA endeavors while also conditioning the range of relevant institutional contexts. Meyer (2015) enumerates the strategic motives for MNEs to engage in FDI operations as follows: market seeking, efficiency seeking, natural resource seeking, and strategic asset seeking. Each motive poses different legitimacy needs and offers a range of strategies from which MNEs must opt for. Therefore, these starting conditions demand further research. This investigation will enhance our understanding about how the complex relationship between legitimacy and MNEs' motives for engaging in a CBA influences MNEs' ownership strategies.

Third, this study did not control for the existence of legitimacy spillover effects related with possible prior assumptions laying in the minds of host countries constituencies regarding a given AfMNE. Kostova and Zaheer (1999, p. 75) state that "the legitimacy of a foreign subsidiary may be judged based on the legitimacy of all subsidiaries of that MNE or of all subsidiaries of the same home country in that host country". The legitimacy spillover effect can be either positive or negative, and the authors posit that it is particularly relevant for MNEs. For example, it is quite likely that a host firm would try to avoid a partnership with an African company due to prior illegitimate procedures made by other African firm as seen by the host country 
legitimating actors. This effect was not controlled for. By controlling the host country propensity to engage in international business relationships with a homogeneous group of MNEs will enhance our knowledge about the appropriateness of ownership strategies under the presence or absence of prior stereotypes towards the acquirer firms.

Fourth, this study did not control for the existence of psychic distance stimuli dimensions, such as religion, form of government or ethnic background (Dow \& Karunaratna, 2006) which may exacerbate legitimacy challenges that AfMNEs face abroad. These specific cross-country distance effects pose hurdles for the achievement of legitimacy by AfMNEs not only because of the colonial past of the whole continent but also because Africa is being built upon a wide variety of ethnicities, often hostile among themselves. Therefore, controlling for these cross-country effects on AfMNEs ability to gain legitimacy abroad may also enhance our understanding over how ownership strategies are adapted accordingly.

Finally, although the size of the acquirer firm may impact its ownership stake choices (Chari \& Chang, 2009) this study does not distinguish between small and large firms. The access to resources, the establishment of political ties, or the embeddedness in network membership can all be affected by firm's dimension, and impact both managers' cross-country distance perceptions and firms' legitimacy needs and paths. Future research needs to deeper investigate the impact in AfMNEs strategic choices resulting from the interaction between the range of cross-national differences and the level of institutional development of the host country, while assessing for firm size. Berry et al. (2010) provide nine different institutional dimensions for measuring crosscountry differences. Considering the international business subject, a complete understanding of the institutional effects over MNEs strategic choices seems to require the integration of the concepts of legitimacy and institutional distance and relate them with particular firm idiosyncrasies, namely the size of the acquirer company.

\subsection{Managerial implications}

This study has important implications for organizations and managerial practice. To begin with, managers should not exaggerate cross-country distance perceptions because it may "lead managers to forego profitable business opportunities" (Håkanson $\&$ Ambos, 2010, p. 195). This opportunity cost might be quite substantial if the manager focuses exclusively in cross-country distance dimensions while disregarding the possibility of effortlessly obtaining legitimacy when entering a foreign market. 
This study also outlines that the level of institutional development in the host country is an important determinant for MNEs ownership stake choices. Two practical consequences emerge. First, because cross-country distance perception is somehow firm specific, managers should carefully analyze the institutional context before mimicking other foreign firms' behavior in a given foreign market. Second, the evaluation of the value of a possible CBA depends on the available strategies for the MNE, such as the ownership stake choice appropriate for the endeavor. Hence, the level of institutional development of the host country becomes crucial to assess the potential value of a CBA.

Managers should examine carefully the appropriateness of their own previous strategies eventually used in prior CBAs because different institutional contexts may lead to a different set of effective strategies. Thus it is advisable to avoid the impulsive and convenient enforcement of personal strategic preferences when engaging in the CBA process. A preference for a full ownership stake might be suitable for a given institutional context, whilst a partial ownership stake might be better for successfully engage in a CBA in another institutional setting. Ultimately, this study alerts managers for integrating both cross-country distance and legitimacy examinations when performing their due diligence efforts because it can help their effectiveness dealing abroad with the market, potential partners and competition. 


\section{Conclusion}

This study evidences that the general theoretical notion that higher cross-national distance instances lead to lower equity control choices only applies in a narrow situational institutional context and does not cover all legitimating factors MNEs need to consider for successfully drawing their international business strategies.

AfMNEs' ownership stake choices are definitely affected by the different institutional contexts firms are faced with. The propensity for pursuing a full ownership acquisition is enhanced by the level of institutional development of the host country. However, cross-country distance perceptions and relevance are firm specific, and ownership stake choices must adjust accordingly. Nonetheless, regardless of firm idiosyncrasies, the effects of unfamiliar environments over AfMNEs are magnified in the presence of institutional voids in the host country.

This study rests on the assumption that each foreign firm face specific institutional pressures abroad and that these pressures may differ from firm to firm. The literature over institutional theory highlights the challenges that gaining legitimacy abroad presents to every MNE. Ownership strategies help MNEs deal with their legitimating audiences, both abroad and internally, and need to be adjusted according to each acquirer firm's idiosyncrasies (Meyer et al., 2014; Kostova et al., 2008).

Herein, and regarding ownership stake choices in a CBA, this study outlines that cross-national distance and legitimacy need to be considered in tandem when MNEs are setting up their strategies. "Institutional-based view on business strategy focuses on the dynamic interaction between institutions and organization, and considers strategic choices as the outcome of such interaction" (Peng, 2002, p. 253). Strategic choices are dependent on MNE managers' perceptions regarding cross-country distance issues and legitimacy concerns (Kostova \& Zaheer, 1999; Shenkar et al., 2008; Dikova, 2009; Sousa \& Lages, 2011). Also, the African CBA context seems to step up this liaison by providing a heterogeneity of institutional contexts either in what concerns cross-national differences and when considering the level of institutional development in the host country.

It is worth remembering the argument that AfMNEs are likely to face greater difficulties to achieve legitimacy abroad than those presented to MNEs from more 
developed origins. One major concern highlighted in the literature regarding the legitimacy problem is the mutual need that the firm and its legitimating environment have for gathering information to address the processes of interpretation, evaluation and understanding each other (Kostova \& Zaheer, 1999). This accrued effort for successfully obtaining legitimacy abroad is higher for AfMNEs even when comparing with other non-African countries coming from emerging economies.

Supported by the differences between the chosen ownership strategies of South African MNEs and non-South African AfMNEs, results strongly suggest that governmental and supranational organizations can play an important role assisting AfMNEs gaining legitimacy abroad and reducing the managers' perception of crosscountry institutional distances. These organizations may complement the important role of cross-national trade agreements to facilitate the achievement of legitimacy, which has been previously outlined by the literature (Brewer, 2007).

Furthermore, this study highlights that gaining legitimacy abroad presents a crucial challenge for the success of any MNE engaging in a CBA. Ownership strategies can be a useful tool enabling MNEs coming from a priori illegitimated locations to succeed in their international endeavors. However, it is worth mentioning that the appropriate ownership strategy is dependent on the combination of firm specificities with the relevant institutional context. Gaining legitimacy abroad may require specific capabilities, such as the MNEs' proficiency developing political ties and/or network relationships, but the need and effectiveness of these capabilities is often linked to the level of institutional development in the host country.

I conclude that the relevant institutional context is composed by the existence of home and host country institutional voids in combination with other international business deterrents at the realm of institutional theory, such as factors of cross-national differences. The literature outlines the scope for MNEs capabilities to be effective when dealing with strong or weak institutional environments for achieving legitimacy abroad (Estrin et al., 2016; Peng, 2003). Research also highlights the effects of cross-national distance on MNEs decision-making process (Johanson \& Vahlne, 1977, 2009; Dow \& Karunaratna, 2006; Brewer, 2007; Håkanson \& Ambos, 2010; Swoboda et al., 2015; Berry et al., 2010) and legitimacy achievement (Kostova \& Zaheer, 1999). Thus, it is important to understand their combined effects in order to draw effective strategies for coping with environmental challenges. Regardless how far the host country might be, in institutional terms, MNEs coming from underdeveloped economies and facing 
pejorative stereotypes abroad still can delineate a successful strategy for gaining legitimacy in the host country. 


\section{References}

Abotsi, A., \& Iyavarakul, T. (2015). Tolerable level of corruption for foreign direct investment in Africa. Contemporary Economics, 9(3), 249-270.

Ando, N. (2012). The ownership structure of foreign subsidiaries and the effect of institutional distance: A case study of Japanese firms. Asia Pacific Business Review, 18(2), 1259-274.

Ang, S., Benirschke, M., \& Doh, J. P. (2015). The interactions of institutions on foreign market entry mode. Strategic Management Journal, 36(10), 1536-1553.

Arslan, A., \& Larimo, J. (2011). Greenfield investmenst or acquisitions: Impacts of Institutional Distance on establishment mode choice of multinational enterprises in emerging economies. Journal of Global Marketing, 24(4), 345-356.

Aybar, B., \& Ficici, A. (2009). Cross-border acquisitions and firm value: An analysis of emerging-market multinationals. Journal of International Business Studies, 40(8), 1317-1338.

Berry, H., Guillén, M., \& Zhou, N. (2010). An institutional approach to cross-national distance. Journal of International Business Studies, 41(9), 1460-1480.

Brewer, P. (2007). Operationalizing psychic distance: A revised approach. Journal of International Marketing, 15(1), 44-66.

Brouthers, K., \& Brouthers, L. (2000). Acquisition or greenfield start-up? Institutional, cultural and transaction costs influences. Strategic Management Journal, 21(1), 89-97.

Brouthers, K., \& Brouthers, L. (2001). Explaining the national cultural distance paradox. Journal of International Business Studies, 32(1), 177-189.

Bruton, G., Peng, M., Ahlstrom, D., Stan, C. and Xu, K. (2015). State-owned enterprises around the world as hybrid organizations. Academy of Management Perspectives, 29(1), 92 - 114

Chan, C., Isobe, T., \& Makino, S. (2008). Which country matters? Institutional development and foreign affiliate performance. Strategic Management Journal, 29(11), 1179-1205.

Chari, M., \& Chang, K. (2009). Determinants of the share of equity sought in crossborder acquisitions. Journal of International Business Studies, 40(8), 1277-1297. 
Chen, R., Cui, L., Li, S., \& Rolfe, R. (2016). Acquisition or greenfield entry into Africa? Responding to institutional dynamics in an emerging continent. Global Strategy Journal, accepted manuscipt. doi: 10.1111/gsj.1154.

Chen, V., Li, J. \& Shapiro, D. (2012). International reverse spillovers: Evidences from emerging-markets MNEs in developed markets. European Management Journal, 30(3), 204-218.

Dacin, M. (1997). Isomorphism in context: The power and prescription of institutional norms. Academy of Management Journal, 40(1), 46-81.

De Beule, F., Elia, S., \& Piscitello, L. (2014). Entry and access to competencies abroad: Emerging market firms versus advanced market firms. Journal of International Management, 20(2), 137-152.

De Villa, M., Rajwani, T., \& Lawton, T. (2015). Market entry modes in a multipolar world: Untangling the moderating effect of the political environment. International Business Review, 24(3), 419-429.

Delios, A., \& Henisz, W. (2000). Japanese firms' investment strategies in emerging economies. Academy of Management Journal, 43(3), 305-323.

Dikova, D. (2009). Performance of foreign subsidiaries: Does psychic distance matter? International Business Review, 18(1), 38-49.

Dikova, D., \& Brouthers, K. (2016). International establishment mode choice: Past, present and future. Management International Review, 56(4), 489-530.

Dow, D., \& Ferencikova, S. (2010). More than just national cultural distance: Testing new distance scales on FDI in Slovakia. International Business Review, 19(1), 4658.

Dow, D., \& Karunaratna, A. (2006). Developing a multidimensional instrument to measure psychic distance stimuli. Journal of International Business Studies, 37(5), 578-602.

Dow, D. \& Larimo, J. (2009). Challenging the conceptualization and measurement of distance and international experience in entry mode choice research. Journal of International Marketing, 17(2), 74-98.

Dow, D. \& Larimo, J. (2011). Disentangling the roles of international experience and distance in establishment mode choice. Management International Review, 51(3), 321-355. 
Elango, B., Lahiri, S., \& Kundu, K. (2013). How does firm experience and institutional distance impact ownership choice in high-technology acquisitions. $R \& D$ Management, 43(5), 501-516.

Elango, B., \& Pattnaik, C. (2011). Learning before making the big leap. Management International Review, 51(4), 461-481.

Estrin, S., Meyer, K., Nielsen, B., \& Nielsen, S. (2016). Home country institutions and the internationalization of state owned enterprises: A cross-country analysis. Journal of World Business, 51(2), 294-307.

Euromoney (2016). Special Report: Africa FX. Online Available: http://www.euromoney.com/page/200807/special-reports.html [Accessed on 23 Feb 2017].

Fairchild, A., \& MacKinnon, D. (2009). A general model for testing mediation and moderation effects. Prevention Science, 10(2), 87-99.

Ferreira, M., Serra, F., \& Reis, N. (2011). On the adaptation of the firm to the international business environment. European Journal of International Management, 5(6), 633-655.

Gaur, A., \& Lu, J. (2007). Ownership strategies and survival of foreign subsidiaries: Impact of Institutional distance and experience. Journal of Management, 33(1), 84-110.

George, G., Corbishley, C., Khayesi, J., Haas, M., \& Tihanyi, L. (2016). Bringing Africa in: Promising directions for management research. Academy of Management Journal, 59(2), 377-393.

Håkanson, L., \& Ambos, B. (2010). The antecedents of psychic distance. Journal of International Management, 16(3), 195-210.

Harzing, A. (2002). Acquisitions versus greenfield investments: International strategy and management of entry modes. Strategic Management Journal, 23(3), 211-227.

Hernández, V., \& Nieto, M. (2015). The effect of the magnitude and direction of institutional distance on the choice of international entry modes. Journal of World Business, 50(1), 122-132.

Hofstede, G. (1984). Cultural dimensions in management and planning. Asia Pacific Journal of Management, 1(2), 81 - 99

Hofstede, G. (1993). Cultural constraints in management theories. Academy of Management Executive, 7(1), 81 - 93 
Hoskisson, R., Wright, M., Filatotchev, I., \& Peng, M. (2013). Emerging multinationals from mid-range economies: The influence of institutions and factor markets. Journal of Management Studies, 50(7), 1295-1321.

Johanson, S., \& Provan, K. (2000). Legitimacy building in the evolution of small-firms multilateral networks: A comparative study of success and demise. Administrative Science Quarterly, 45(2), 327-365.

Johanson, J., \& Vahlne, J. (1977). The internationalization process of the firm: A model of knowledge development and increasing foreign market commitments. Journal of International Business Studies, 8(1), 23-32.

Johanson, J., \& Vahlne, J. (2009). The Uppsala internationalization process model revisited: From liability of foreignness to liability of outsidership. Journal of International Business Studies, 40(9), 1411-1431.

Johanson, J., \& Wiedersheim-Paul, F. (1975). The internationalization of the firm: Four Swedish cases. Journal of Management Studies, 12(3), 305-322.

Kedia, B., \& Bilgili, T. (2015). When history matters: The effect of historical ties on the relationship between institutional distance and shares acquired. International Business Review, 24(6), 921-934.

Khanna, T., \& Palepu, K. (2000). Is group affiliation profitable in emerging markets? An analysis of diversified Indian business groups. The Journal of Finance, 55(2), 867-891.

Kogut, B., \& Singh, H. (1988). The effect of national culture on the choice of entry mode. Journal of International Business Studies, 19(3), 411-432.

Kostova, T., Roth, K., \& Dacin, M. (2008). Institutional theory in the study of multinational corporations: A critique and new directions. Academy Management Review, 33(4), 994-1006.

Kostova, T., \& Zaheer, S. (1999). Organizational legitimacy under conditions of complexity: The case of the multinational enterprise. Academy Management Review, 24(1), 64-81.

La Porta, R., Lopez-de-Silanes, F, Shleifer, A., \& Vishny, R. (1998). Law and finance. Journal of Political Economy, 106(6), 1113-1155.

Laufs, K., \& Schwens, C. (2014). Foreign market entry mode choice of small and medium-sized enterprises: A systematic review and future research agenda. International Business Review, 23(6), 1109-1126. 
Lebedev, S., Peng, M., Xie, E., \& Stevens, C. (2015). Mergers and acquisitions in and out of emerging economies. Journal of World Business, 50(4), 651-662.

Li, Y., Chen, H., Liu, Y., \& Peng, M. (2014). Managerial ties, organizational learning, and opportunity capture: A social capital perspective. Asia Pacific Journal of Management, 31(1), 271-291.

Li, Y., Peng, M., \& Macaulay, C. (2013). Market-political ambidexterity during institutional transitions. Strategic Organization, 11(2), 205-213.

Lin, Z., Peng, M., Yang, H., \& Sun, S. (2009). How do networks and learning drive M\&As? An institutional comparison between China and the United States. Strategic Management Journal, 30(10), 1113-1132.

Lu, Y., Tsang, E., \& Peng, M. (2008). Knowledge management and innovation strategy in the Asia Pacific: Toward an institution-based view. Asia Pacific Journal of Management, 25(3), 361-374.

Madhok, A. (1997). Cost, value and foreign market entry mode: the transaction and the firm. Strategic Management Journal, 18(1), 39-61.

Meyer, K. (2001). Institutions, transaction costs, and entry mode choice in Eastern Europe. Journal of International Business Studies, 32(2), 357-367.

Meyer, K. (2015). What is "strategic asset seeking FDI"? Multinational Business Review, 23(1), 57-66.

Meyer, K., Ding, Y., Li, J., \& Zang, H. (2014). Overcoming distrust: How state-owned enterprises adapt their foreign entries to institutional pressures abroad. Journal of International Business Studies, 45(8), 1005-1028.

Meyer, K., Estrin, S., Bhaumik, S., \& Peng, M. (2009). Institutions, resources, and entry strategies in emerging economies. Strategic Management Journal, 30(1), 61-80.

Miller, D., \& Shamsie, J. (1996). The resource based-view of the firm in two environments: The Hollywood film studios from 1936 to 1965. Academy of Management Journal, 39(3), 519-543.

Mol, M., Stadler, C., \& Ariño, A. (2016). Africa: The new frontier for global strategy scholars. Global Strategy Journal, accepted.

Murtha, T., \& Lenway, S. (1994). Country capabilities and the strategic state: How national political institutions affect multinational corporations' strategies. Strategic Management Journal, 15(S2), 113-129.

Oliver, C. (1997). Sustainable competitive advantage: Combining institutional and resource based view. Strategic Management Journal, 18(9), 697-713. 
Osabutey, E., Williams, K., \& Debrah, Y. (2014). The potential for technology and knowledge transfer between foreign and local firms: A study of the construction industry in Ghana. Journal of World Business, 49(4), 560-571.

Peng, M. (2002). Towards an institution-based view of business strategy. Asia Pacific Journal of Management, 19(2), 251-267.

Peng, M. (2003). Institutional transitions and strategic choices. Academy of Management Review, 28(2), 275-296.

Peng, M., Sun, S., Pinkham, B., \& Chen, H. (2009). The institutional-based view as a third leg for a strategy tripod. Academy of Management Perspectives, 23(3), 6381.

Peng, M. (2012). The global stratey of emerging multinationals from China. Global Strategy Journal, 2(2), 97-102.

Risberg, A. (2003). The merger and acquisition process. Journal of International Business Studies. Retrieved from http://www.jibs.net

Rugman, A., Verbecke, A., \& Nguyen, Q. (2011). Fifty years of international business theory and beyond. Management International Review, 51(6), 755-786.

Scott, W. (2004). Institutional theory: Contributing to a theoretical research program. Stanford University, Oxford University Press, 1-47.

Shenkar, O. (2001). Cultural distance revisited: Towards a more rigorous conceptualization and measurement of cultural differences. Journal of International Business Studies, 32(3), 519-535.

Shenkar, O., Luo, Y., \& Yeheskel, O. (2008). From "distance" to "friction": Substituting metaphors and redirecting intercultural research. Academy of Management Review, 33(4), 905-923.

Sousa, C., \& Lages, L. (2011). The PD Scale: A measure of psychic distance and its impact on international marketing strategy. International Marketing Review, 28(2), 201-222.

Suchman, M. (1995). Managing legitimacy: strategic and institutional approaches. The Academy of Management Review, 20(3), 571-610.

Sun, S., Peng, M., Ren, B., \& Yan, D. (2012). A comparative ownership advantage framework for cross-border M\&As: The rise of Chinese and Indian MNEs. Journal of World Business, 47(1), 4-16. 
Swoboda, B., Elsner, S., \& Olejnik, E. (2015). How do past mode choices influence subsequent entry? A study on the boundary conditions of preferred entry modes of retail firms. International Business Review, 24(3), 506-517.

Teece, D., Pisano, G., \& Shuen, A. (1997). Dynamic capabilities and strategic management. Strategic Management Journal, 18(7), 509-533.

Tykvová, T., \& Schertler, A. (2014). Does syndication with local venture capitalists moderate the effects of geographical and institutional distance? Journal of International Management, 20(4), 406-420.

Weigelt, C., \& Miller, D. (2013). Implications of internal organization structure for firm boundaries. Strategic Management Journal, 34(12), 1411-1434.

White III, G., Boddewyn, J., \& Galang, R. (2015). Legal system contingencies as determinants of political tie intensity by wholly owned foreign subsidiaries: Insights from the Philippines. Journal of World Business, 50(2), 342-356.

World Bank (2015). World Development Indicators. Online Available: http:// http://data.worldbank.org/products/wdi [Accessed on 22 Nov 2016].

Xu, D., \& Shenkar, O. (2002). Institutional distance and the multinational enterprise. Academy of Management Review, 27(4), 608-618. 